Document downloaded from:

http://hdl.handle.net/10251/60828

This paper must be cited as:

Guacaneme Moreno, JA.; Gabriel Garcerá; Figueres Amorós, E.; Patrao Herrero, I.; González Medina, R. (2015). Dynamic modeling of a dual active bridge DC to DC converter with average current control and load-current feed-forward. International Journal of Circuit Theory and Applications. 43(10):1311-1332. doi:10.1002/cta.2012.

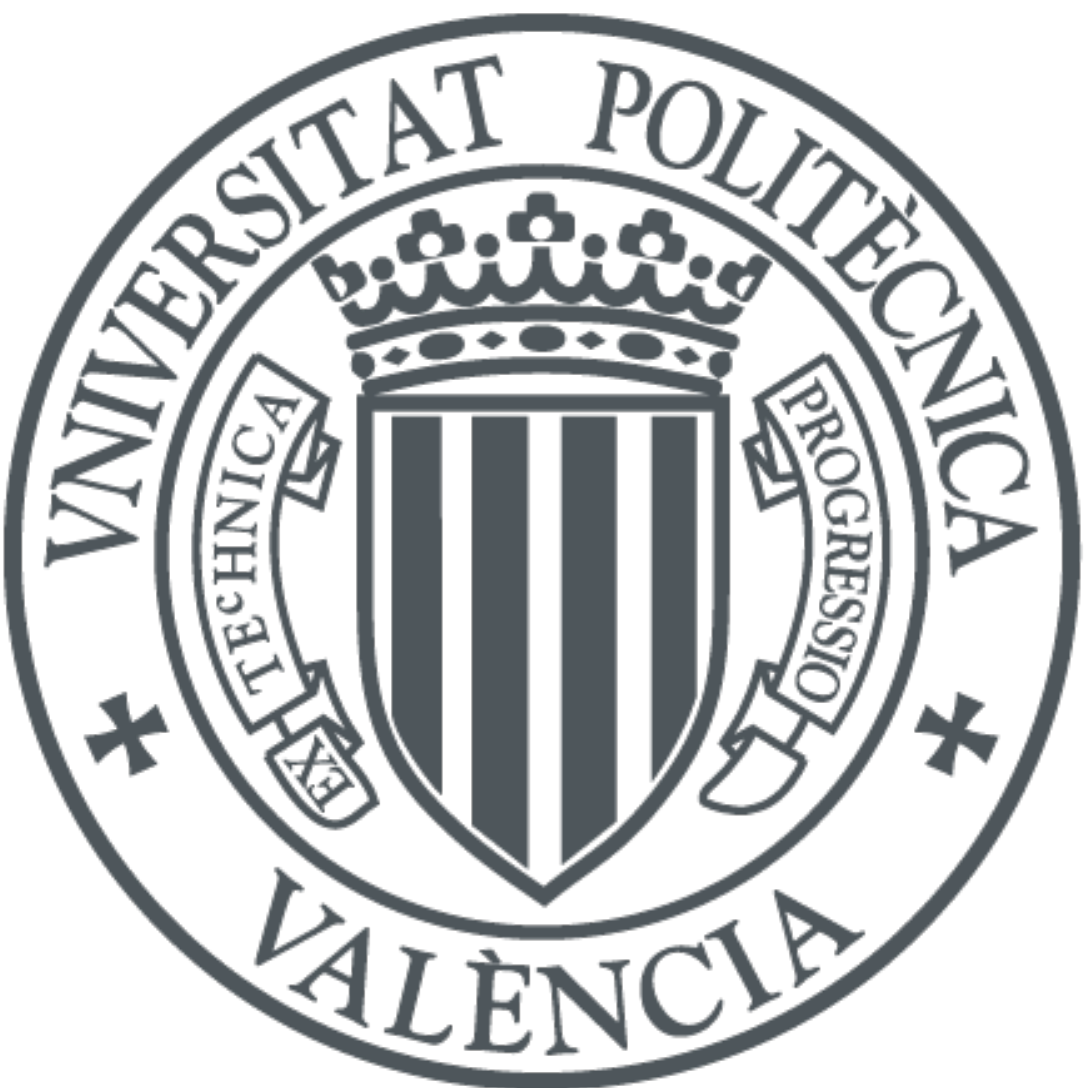

The final publication is available at

http://dx.doi.org/10.1002/cta.2012

Copyright Wiley

Additional Information 


\title{
Dynamic modeling of a dual active bridge DC to DC converter with average current control and load-current feed-forward
}

\author{
Javier Guacaneme ${ }^{1,2}$, Gabriel Garcerá ${ }^{1}$, Emilio Figueres ${ }^{1}$, \\ Iván Patrao ${ }^{1}$ and Raúl González-Medina ${ }^{1}$ \\ ${ }^{1}$ Grupo de Sistemas Electrónicos Industriales del Departamento de Ingeniería \\ Electrónica, Universitat Politécnica de Valencia \\ ${ }^{2}$ Laboratorio de Investigación en Fuentes Alternativas de Energía, \\ Universidad Distrital Francisco José de Caldas
}

Correspondence to: Javier Guacaneme. E-mail: jaguamo@posgrado.upv.es Tel:+34 603105501

\section{SUMMARY}

Bidirectional power flow is needed in many power conversion systems like energy storage systems, regeneration systems, power converters for improvement of the power quality and some DC-DC applications where bidirectional high power conversion and galvanic isolation are required. The Dual Active Bridge (DAB) is an isolated, high voltage ratio DC-DC converter suitable for high power density and high power applications, being a key interface between renewable energy sources and energy storage devices. This paper is focused on the modeling and control design of a DC-DC system with battery storage based on a DAB converter with average current mode control of the output current and output voltage control. The dynamic response of the output voltage to load steps is improved by means of an additional load-current feedforward control loop. An analytical study of the load-current feed-forward is presented and validated by means of both simulations and experimental results.

KEY WORDS: DC-DC power conversion; dual active bridge; current mode control; feed-forward; modeling.

\section{INTRODUCTION}

The recent development of sustainable and alternative energy sources requires versatile energy management systems capable of adaptation to the discontinued nature of those energy sources. The issue of the sporadic availability of renewable sources (RES) can be addressed by introducing energy storage systems (ESS) to decouple the energy generation from its demand [1]. ESS are essentially DC systems, so that bidirectional DC-DC converters are required to manage the energy from and to the DC bus.

Hybrid systems based on RES have been studied in [2-13] as a solution to develop efficient and versatile energy management systems. The key element of those solutions is the bidirectional DC-DC converter, which is widely used in hybrid electric vehicles $[5,10]$, uninterruptible power systems UPS [9], power distribution systems [8,11], electric aircraft systems [12], grid connected PV systems [13] and other applications. As depicted in figure 1, a bidirectional DC-DC converter enables the bidirectional and isolated power flow in systems which use battery banks to provide grid support. On one 
hand, the difference between the battery voltage and the DC link voltage may require an interface with the right voltage ratio. On the other hand, safety regulations may require galvanic isolation in the DC-DC converter. In those cases the use of a high frequency transformer embedded in the DC-DC converter is mandatory $[14,15]$.

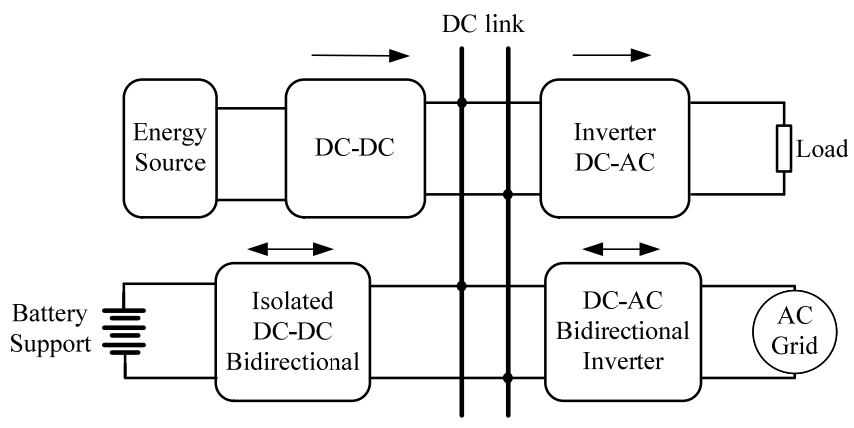

Figure 1 . Hybrid energy system with battery backup

The Dual Active Bridge (DAB) DC-DC converter was proposed in [2] and [3] for high power density and high power applications. It operates at a fixed switching frequency with soft-switching, providing high-frequency isolation, bidirectional power and the necessary voltage ratio. The DAB converter can be used in high power density systems which require galvanic isolation between two DC buses working at quite different voltage levels.

Efficiency is a key feature in energy storage systems. Advances in semiconductor devices technology and new control algorithms for expanding the soft switching range, [10], [16] and [17], have achieved efficiencies higher than $97 \%$.

The basic scheme of a DAB converter is shown in figure 2. Two active bridges are linked by means of a series $\mathrm{AC}$ inductor and a high frequency transformer. In some cases an external AC inductor is not required, because its function is performed by the transformer leakage inductance. Input and output capacitors are necessary to provide filtering. The current ripple in those capacitors is usually very high.

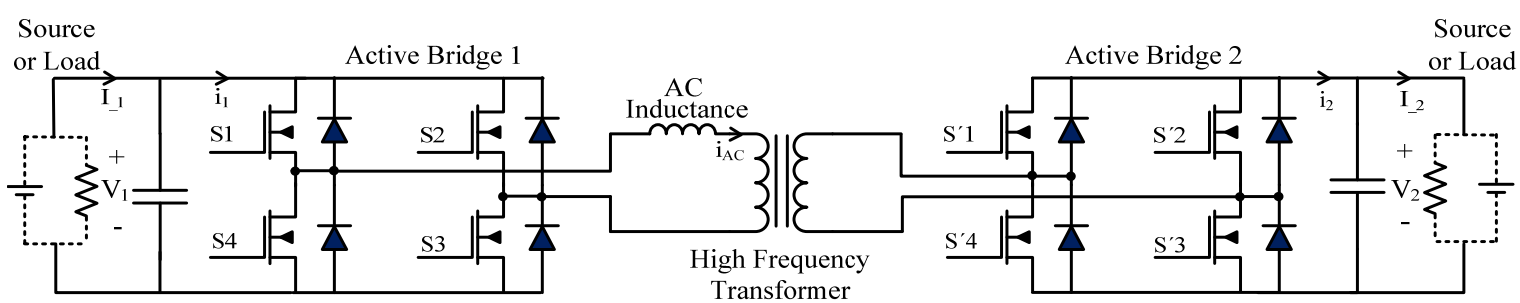

Figure 2. Basic scheme of a Dual Active Bridge converter.

A dynamic model of the DAB converter is necessary to design the controllers of the input or output variables. The conventional state space averaging method [18] is not applicable for the dynamic analysis of the $\mathrm{DAB}$, because the average value of the $\mathrm{AC}$ inductor current $\left(i_{\mathrm{AC}}\right)$ is always zero over one switching cycle, so that it is not possible to use that current as a state variable. However, the AC inductor has a high frequency 
dynamics because of its small value, so that it can be neglected in a low frequency dynamic model. The DC link currents of the DAB averaged over one switching cycle, $\left\langle i_{1}\right\rangle$ and $\left\langle i_{2}\right\rangle$, are considered as current sources controlled by the phase shift between the input and the output bridge. This assumption is valid for both the steady and the transient state.

When the input and output control variables of a power converter are defined, the operating conditions determine the steady state values of those variables and their dynamic behavior. The small-signal model of the DAB can be derived by the linearization of the static control-to-output characteristics of the converter around the operating point.

Several DAB modeling studies have proposed voltage mode control strategies: a discrete model using half wave symmetry [19,20], a dynamic model based on harmonics [21], a hybrid control like traditional PI based feedback and feed-forward of an estimation of the phase-shift [22] or feed-forward of the load current [23]. This paper is focused on the analysis and control design of the DAB with Average Current Mode Control (ACC) [24], a cascade control structure with an inner current loop and an outer voltage loop. A small-signal model of ACC is developed. The dynamic response to load variations is improved by means of load current feed-forward.

\section{DAB CONVERTER OPERATION}

The proposed system uses a $\mathrm{DAB}$ for bidirectional energy management between a battery bank of $24 \mathrm{~V}$ and a DC power bus of $400 \mathrm{~V}$, with ACC and load current feedforward. The inner control loop adjusts the required current on the high voltage side and the superimposed voltage control loop regulates the output voltage. The parameters of the DAB converter under study are summarized in table I.

Figure 3 shows a simplified model of the DAB converter in boost configuration $\left(V o / N_{21}>V i\right)$, where the power flows from $\mathrm{V}_{\mathrm{i}}$ to $\mathrm{V}_{\mathrm{O}} . \phi$ is the phase shift between the input and the output bridge, expressed in radians. The bridges are phase-shifted to control the power flow from the DC voltage source $\left(\mathrm{V}_{\mathrm{i}}\right)$, connected to the leading bridge ( 0 phase shift), to the output $\left(V_{O}\right)$, connected to the lagging bridge ( $\phi \phi$ phase shift). When the phase of output bridge is lagging $(\phi>0)$, the power flows from $V_{i}$ to $V_{O}$. $L$ represents the transformer leakage inductance plus the inductance of an auxiliary external inductor referred to primary side.

The parameter $d$ stands for the primary-referred DC voltage gain of the converter or effective duty ratio, $d=\left(V_{o} / N_{21}\right) / V_{i}=V_{o}$ ' $/ V_{i}$. Forward or reverse power flow with Zero Voltage Switching (ZVS) is achievable over the whole operating range for $d=1$. For different values of $d,(d<1, d>1)$, the soft switching operation range is reduced. The soft switching range decreases under light loads [25]. 


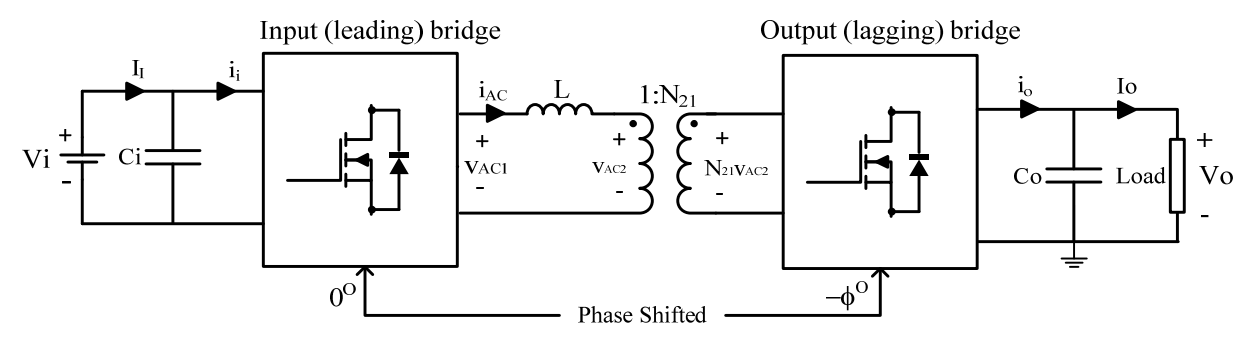

Figure 3. Simplified model of a DAB controlled by the phase shift $\phi$.

The ideal simulation waveforms of the DAB converter in boost configuration, where $V o / N_{21}>V i$, are depicted in Figure 4. The square voltage waveforms $\mathrm{v}_{\mathrm{AC} 1}$ and $\mathrm{v}_{\mathrm{AC} 2}$ produced by the input and output bridges are phase shifted in order to control the power flow. There are two operation modes in each half switching cycle (modes 1 and 2). The expression of the $\mathrm{AC}$ inductor current, $\mathrm{i}_{\mathrm{AC}}$, as a function of the time angle, $\theta=\omega t$, is shown by (1) and (2), where: $\mathrm{V}_{\mathrm{O}}^{\prime}=\mathrm{V}_{\mathrm{O}} / \mathrm{N}_{21}, \phi$ is the phase shift and $\omega=2 \cdot \pi \cdot \mathrm{f}_{\mathrm{S}}$ is the switching frequency $\left(\mathrm{f}_{\mathrm{S}}\right)$ expressed in $\mathrm{rad} / \mathrm{s}$.

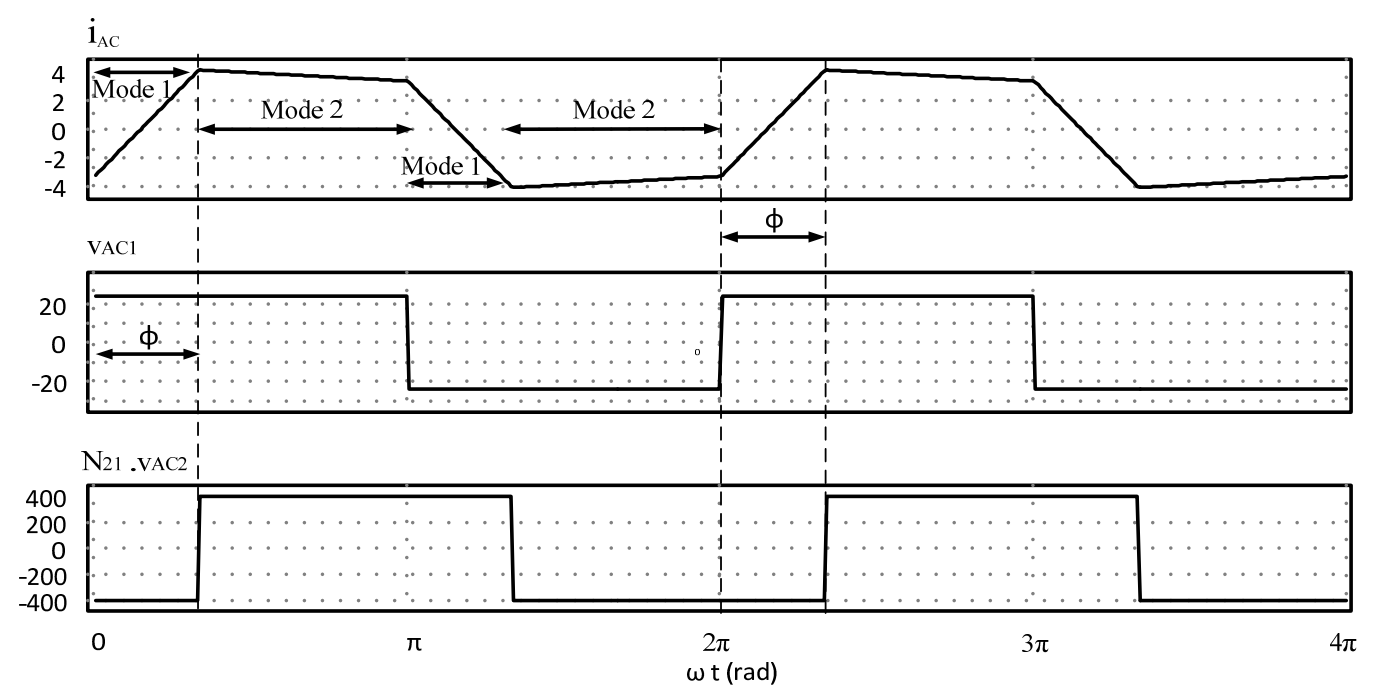

Figure 4. Theoretical DAB converter waveforms in forward mode $(\phi>0)$

In mode $1: 0 \leq \theta<\phi ; v_{a c 1}=V i ; v_{a c 2}=-V o^{\prime}$

$$
i_{A C}(\theta)=\frac{\left[V_{i}+V o^{\prime}\right]}{\omega L}(\theta)+i_{A C}(0)
$$

, where $\mathrm{i}_{\mathrm{AC}}(0)$ is the initial current at $\theta=0$. Mode 1 ends when: $\theta=\phi$.

In mode 2: $\phi \leq \theta<\pi ; \quad v_{a c 1}=V_{i} ; \quad v_{a c 2}=V_{O^{\prime}}$

$$
i_{L F}(\theta)=\frac{\left[V_{i}-V o^{\prime}\right]}{\omega L}(\theta-\phi)+i_{A C}(\phi)
$$


At the end of the half cycle: $i_{\mathrm{AC}}(\pi)=-i_{\mathrm{AC}}(0)$. By solving for $i_{\mathrm{AC}}(0)$ and $i_{\mathrm{AC}}(\phi)$ the complete waveform of $\mathrm{i}_{\mathrm{AC}}(\theta)$ is obtained. The transferred power, $P_{o}$, as a function of the phase shift is described by (3). Note that: $\mathrm{I}_{\mathrm{i}}=\left\langle\mathrm{i}_{\mathrm{i}}\right\rangle$ and that $\mathrm{I}_{\mathrm{O}}{ }^{\prime}=\mathrm{I}_{\mathrm{O}} \cdot \mathrm{N}_{21}=\left\langle\mathrm{i}_{\mathrm{O}}\right\rangle \cdot \mathrm{N}_{21}$.

$$
P o(\phi)=V_{i} I_{i}=V_{o}^{\prime} I_{o}^{\prime}=\frac{V_{i}^{2}}{\omega L} \cdot d \cdot \phi\left[1-\frac{|\phi|}{\pi}\right] \quad-\frac{\pi}{2} \leq \phi \leq \frac{\pi}{2}
$$

Figure 5 depicts $\mathrm{P}_{0}(\phi)$ for $d=1.111$ in the range: $\phi \in[0, \pi / 2]$. The soft-switching region is enclosed within the two ZVS boundaries given by the constraints: $i_{L}(0) \leq 0$ for the input bridge and $i_{L}(\phi) \geq 0$ for the output bridge. It is observed that the value of $\phi$ must be higher than $10^{\circ}$ in order to achieve ZVS of the switching devices of the input bridge.

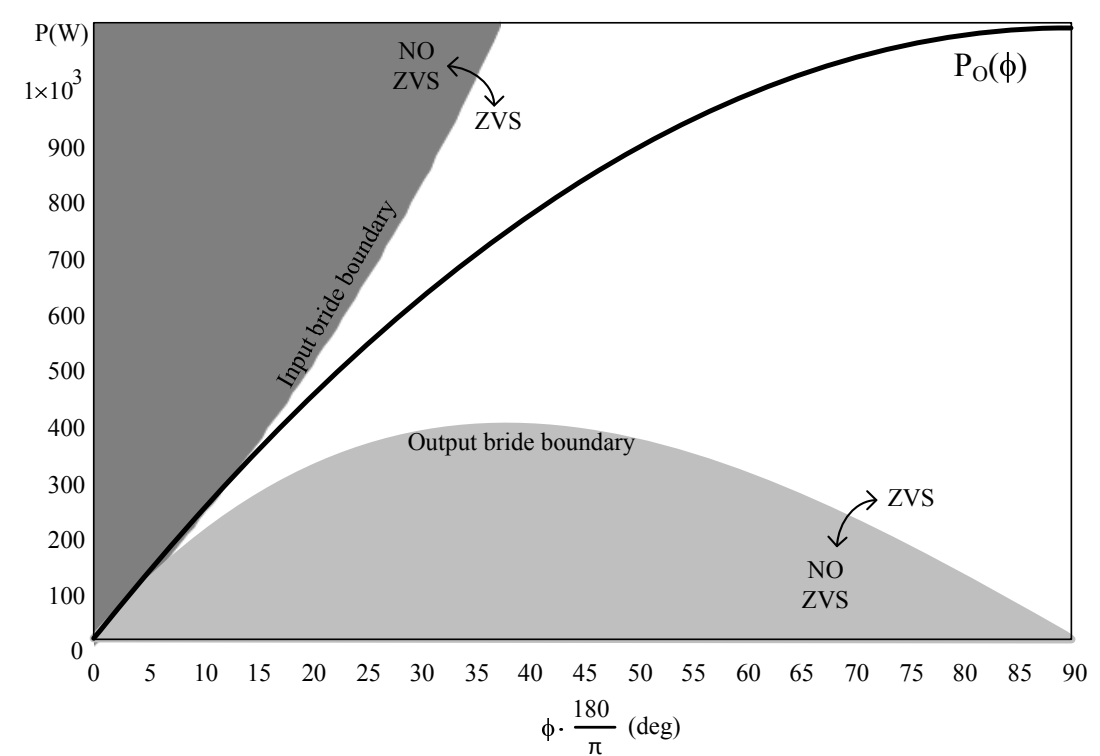

Figure 5. Output power versus $\phi$ for $d=1.111$. The ZVS boundaries of both bridges (input and output) are indicated

\section{MODELING OF THE DAB DC- DC CONVERTER}

Replacing the expression $d=\left(V_{O} / N_{21}\right) / V_{i}=V_{O}^{\prime} / V_{i}$ into (3), the average value of the DAB output current can be expressed by (4), which is valid for both forward $(\phi>0)$ and reverse $(\phi<0)$ power flow. The small-signal model of the DAB converter can be found by averaging and perturbing the dynamic variables around a given operation point, $Q$. The averaged variable $\bar{\imath}_{0}$ is represented as (5), where $I_{0}$ denotes the operation point value and $\hat{\imath}_{0}$ the small-signal term.

$$
\begin{gathered}
i_{O}\left(\phi, v_{i}\right)=\frac{v_{i}}{N_{21} 2 \pi \cdot f_{S} \cdot L} \cdot \phi \cdot\left(1-\frac{|\phi|}{\pi}\right) ; \quad-\frac{\pi}{2} \leq \phi \leq \frac{\pi}{2} \\
\bar{\imath}_{O}=I_{O}+\hat{\imath}_{O}
\end{gathered}
$$

Considering $\hat{\phi}$ the control variable and $\hat{v}_{i}$ the disturbance at the input voltage, the smallsignal dynamic model of the converter is obtained by means of partial derivatives of (4) around $Q$, yielding (6). 


$$
\hat{\imath}_{O}=\left.\frac{\partial i_{O}}{\partial \phi}\right|_{Q} \cdot \hat{\phi}+\left.\frac{\partial i_{O}}{\partial v_{i}}\right|_{Q} \cdot \hat{v}_{i}
$$

The small-signal value of the DAB output current can be expressed as a function of $\hat{\phi}$ and $\hat{v}_{i}$ as (7),

$$
\hat{\iota}_{O}=\frac{V_{i}}{N_{21} \cdot 2 \pi \cdot f_{S} \cdot L} \cdot\left(1-\frac{2 \cdot|\Phi|}{\pi}\right) \cdot \hat{\phi}+\frac{\Phi}{N_{21} \cdot 2 \pi \cdot f_{S} \cdot L} \cdot\left(1-\frac{|\Phi|}{\pi}\right) \cdot \hat{v}_{i}
$$

The static gains defined in (8) depend on the operation point values $V_{i}$ and $\Phi$.

$$
\begin{gathered}
I_{o \phi}=\left.\frac{\hat{\imath}_{O}(s)}{\hat{\phi}(s)}\right|_{\hat{v}_{i}=0}=\frac{V_{i}}{N_{21} \cdot 2 \pi \cdot f_{s} \cdot L} \cdot\left(1-\frac{2 \cdot|\Phi|}{\pi}\right) \\
I_{O_{-} v i}=\left.\frac{\hat{\imath}_{O}(s)}{\hat{v}_{i}(s)}\right|_{\hat{\phi}=0}=\frac{\Phi}{N_{21} \cdot 2 \pi \cdot f_{s} \cdot L} \cdot\left(1-\frac{|\Phi|}{\pi}\right)
\end{gathered}
$$

Replacing (8) in (7) the small-signal value of the DAB output current can be simplified as (9),

$$
\hat{\imath}_{O}=I_{O \phi} \cdot \hat{\phi}+I_{O_{-} v i} \cdot \hat{v}_{i}
$$

A similar analysis can be performed for the input variables, where $V_{o}$ and $\phi$ represent the operation point and $\hat{\phi}$ and $\hat{v}_{o}$ stand for small-signal terms. The static gains and the small-signal expression of the input current are expressed by (10) and (11), respectively.

$$
\begin{gathered}
I_{i \phi}=\left.\frac{\hat{\imath}_{i}(s)}{\hat{\phi}(s)}\right|_{\hat{v}_{O}=0}=\frac{V_{o}}{N_{21} \cdot 2 \pi \cdot f_{s} \cdot L} \cdot\left(1-\frac{2 \cdot|\Phi|}{\pi}\right) \\
I_{i_{-} v o}=\left.\frac{\hat{\imath}_{i}(s)}{\hat{v}_{o}(s)}\right|_{\widehat{\phi}=0}=\frac{\Phi}{N_{21} \cdot 2 \pi \cdot f_{s} \cdot L} \cdot\left(1-\frac{|\Phi|}{\pi}\right) \\
\hat{\imath}_{i}=I_{i \phi} \cdot \hat{\phi}+I_{i_{-} v o} \cdot \hat{v}_{o}
\end{gathered}
$$

The DAB small-signal model summarized by (9) and (11) is depicted in figure 6, where an input and an output channel can be observed. The control loops can control either the input or the output variables. In figure 6 loads placed at the input or at the output are represented as equivalent resistances $\mathrm{R}_{\mathrm{BAT}}$ and $\mathrm{R}_{\mathrm{EQ}}$, respectively. Their use depends on the magnitude to be controlled and on the direction of the power flow. The voltage sources $\hat{v}_{i}$ and $\hat{v}_{o}$ stand for voltage disturbances at the input or at the output, respectively. 


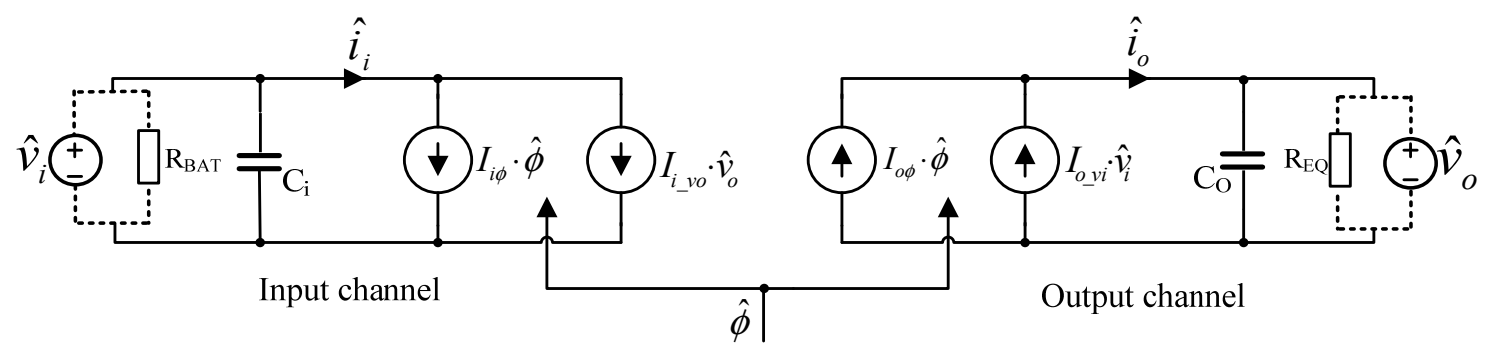

Figure 6. Small-signal model of the DAB input and output channels

Figure 7 shows the small-signal model of the output channel of the DAB converter, which is used when the output voltage is going to be regulated. The values $\hat{i} g$ and $\hat{v}_{i}$ represent the load current and input voltage disturbances, respectively. Using the model of figure 7 and replacing the static gains of (8), the open loop DAB transfer functions can be obtained. They are summarized in Table II. $\mathrm{G}_{\mathrm{V} \phi}(\mathrm{s})$ is the transfer function from the phase shift (control variable) to the output voltage. $A(s)$ is the open-loop audiosusceptibility and $\mathrm{Z}_{\mathrm{O}}(\mathrm{s})$ is the open loop output impedance.

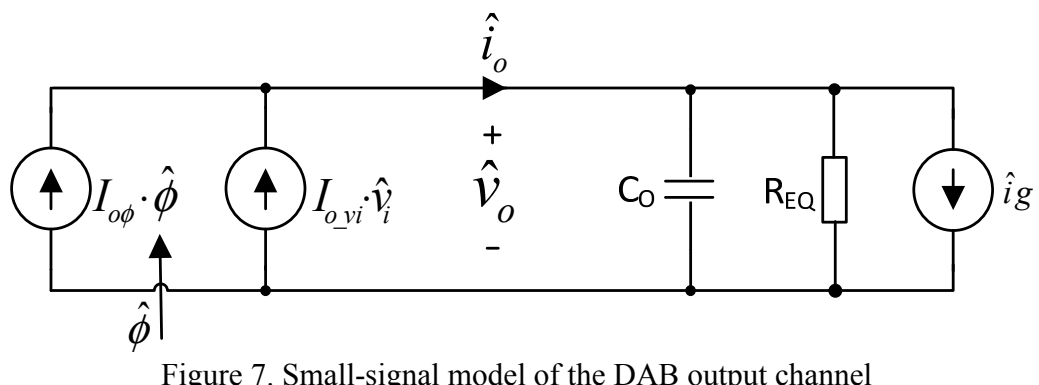

The Bode plots of figures 8,9 and 10 are obtained by inserting the parameters of table I in the open-loop transfer functions of table II. The $\mathrm{G}_{\mathrm{V} \phi}(\mathrm{s})$ and the $\mathrm{A}(\mathrm{s})$ transfer functions are characterized by a first order roll-off.

In figure 8 it is observed the influence of the transferred power on the $\mathrm{DC}$ gain of $\mathrm{G}_{\mathrm{V} \phi}(\mathrm{s})$ in a sweep from $200 \mathrm{~W}$ to $1 \mathrm{~kW}$ : the higher the power, the smaller the DC gain. Besides, it can be observed that the first order pole of $G_{V \phi}(s)$, located at $1 / C \cdot R_{E Q}$, is shifted to higher frequencies when the power is increased. The PI regulator of the current loop is designed taking those variations into account, as it is shown in section 4 . 


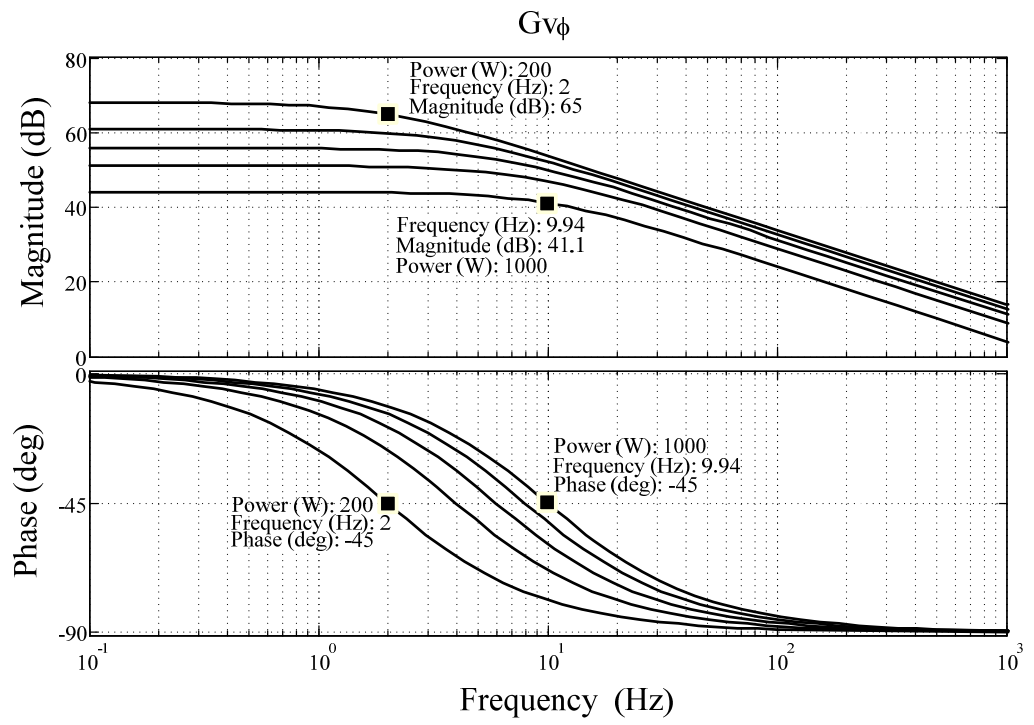

Figure 8. Bode plots of $\mathrm{G}_{\mathrm{V} \phi}(\mathrm{j} \omega)$ as a function of $\mathrm{P} . \mathrm{P}=[200 \mathrm{~W}, 400 \mathrm{~W}, 600 \mathrm{~W}, 800 \mathrm{~W}, 1000 \mathrm{~W}]$

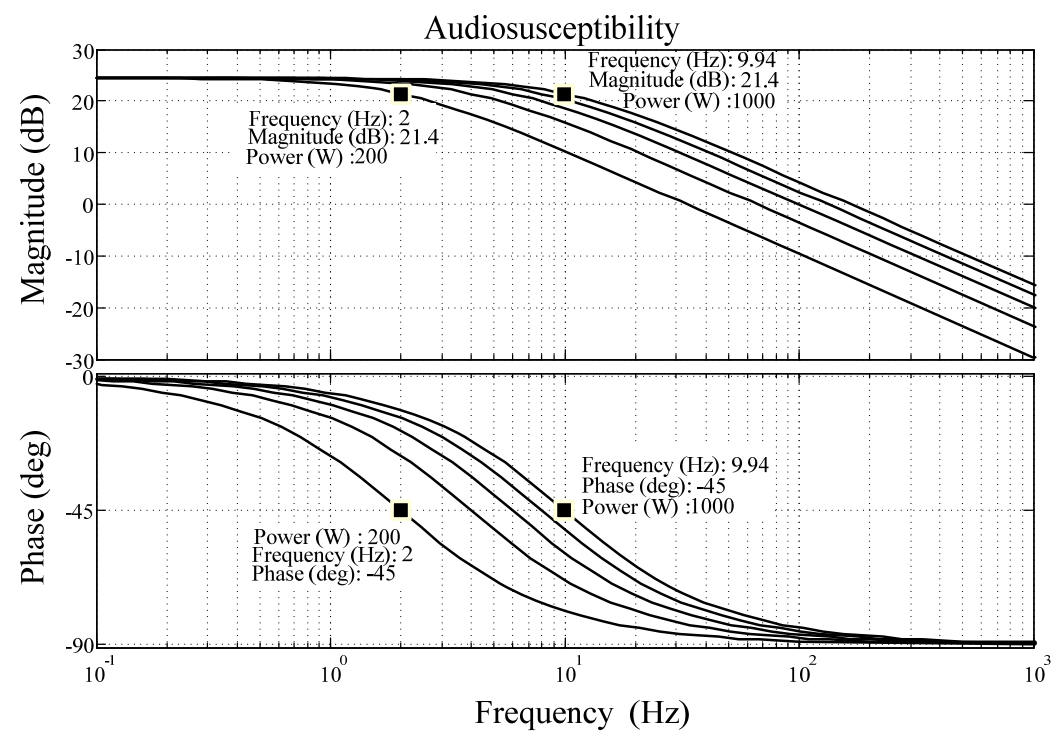

Figure 9. Bode plots of $A(j \omega)$ as a function of $P . P=[200 \mathrm{~W}, 400 \mathrm{~W}, 600 \mathrm{~W}, 800 \mathrm{~W}, 1000 \mathrm{~W}]$.

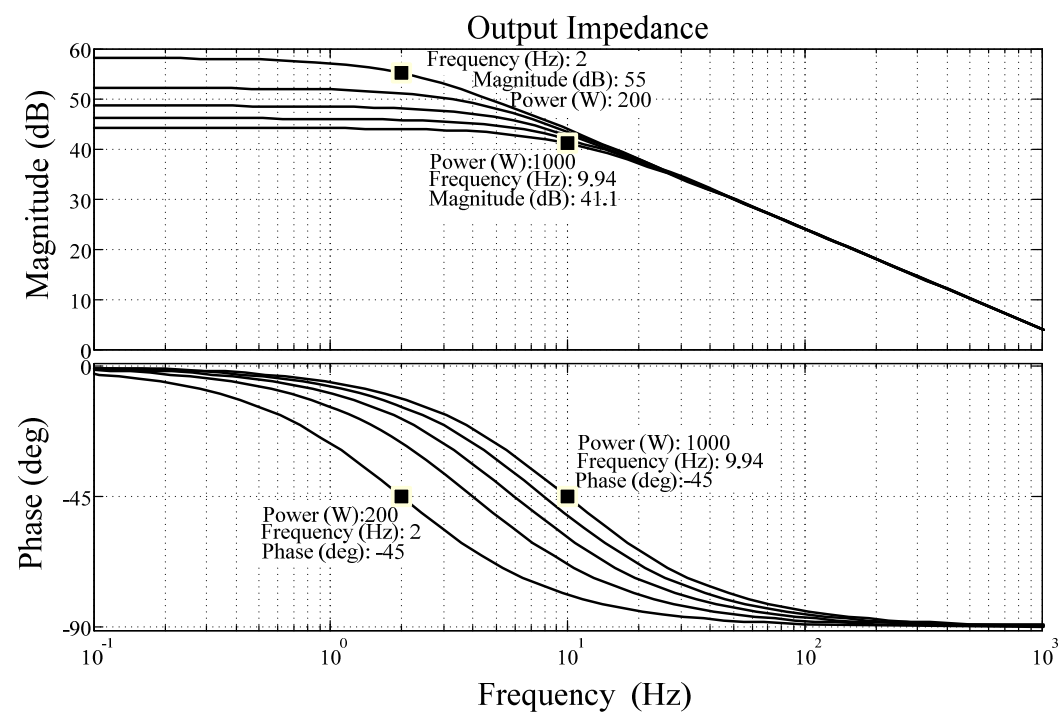




\section{Average Current Control of the DAB CONVERTER}

Figure 11 shows the control scheme of a DAB with ACC and output voltage control. The analog circuit implementation of the control circuit uses the UC3875 phase shift modulator of Texas Instruments. The proposed control is composed by a fast inner current loop and a slower outer voltage loop. In the current loop the output current is measured by means of a current sensor with gain $R i$ and low pass filtered (LPF) to obtain its average value [24,26]. The filtered signal is subtracted from the current reference, $R_{i} \cdot i_{o \_r e f}$, provided by the PI outer voltage controller, $\mathrm{G}_{\mathrm{V}}(\mathrm{s})$. The obtained error becomes the input signal of the PI current controller, $\mathrm{G}_{\mathrm{i}}(\mathrm{s})$, which achieves that the sensed current agrees with the reference current in steady state. The output of the current controller is the modulator voltage $\left(\mathrm{V}_{\mathrm{MOD}}\right)$, which is compared with a sawtooth signal in the phase shift modulator of the UC3875 to obtain the gate signals of the input and output bridges.

The outer voltage loop regulates the output voltage of the DAB converter. The output voltage is sensed with a gain $\beta$, which is subtracted from an external output voltage reference, $\beta \cdot V_{O_{-} R E F}$. The voltage error excites the PI voltage controller, $G_{V}(s)$, whose output is the current reference. The output of the voltage controller is limited to a value that limits the DAB output current, working as an overcurrent protection scheme.

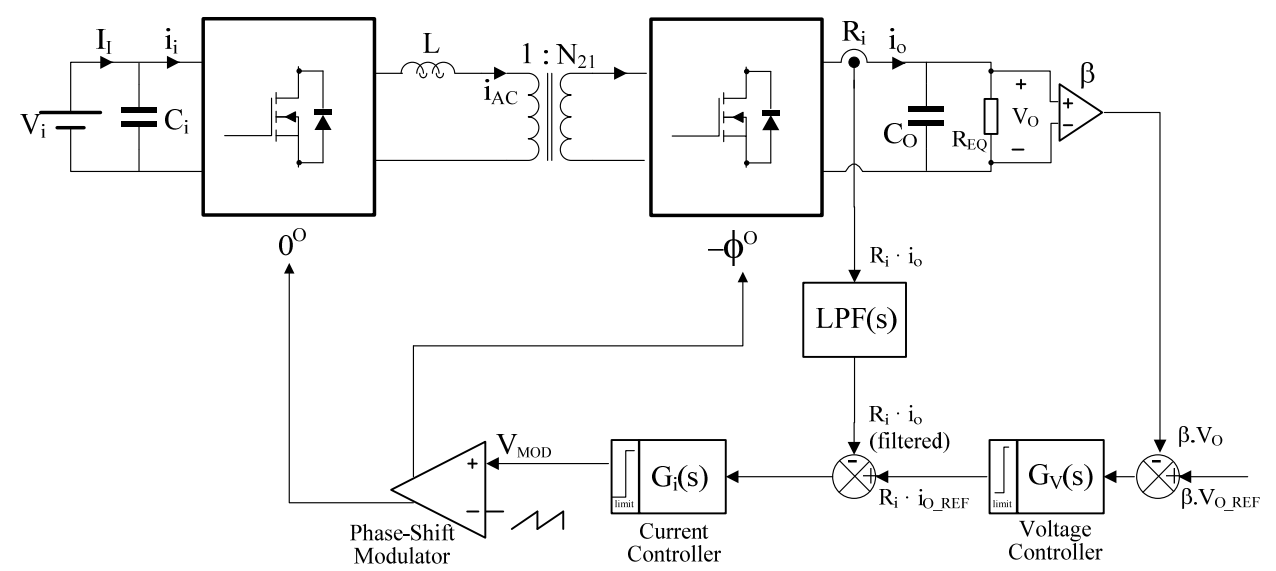

Figure 11. Scheme of a DAB with ACC.

Figure 12 shows the small-signal model of the output channel of the DAB converter with ACC. The input channel affects the output channel as a perturbation, $\hat{v}_{i}$. In figure $12, \mathrm{~F}_{\mathrm{m}}$ represents the phase shift modulator gain. For the UC3875, $\mathrm{F}_{\mathrm{m}}=\pi / \mathrm{V}_{\mathrm{pp}}$, where $\mathrm{V}_{\mathrm{pp}}$ is the peak to peak voltage of the sawtooth signal inside the modulator.

The inner current loop is designed by loop-shaping of the open loop gain, $T_{i}(s)$, expressed by (21). The current controller, $\mathrm{G}_{\mathrm{i}}(\mathrm{s})$, is designed for adequate gain and phase stability margins of $\mathrm{T}_{\mathrm{i}}(\mathrm{s})$. 


$$
T_{i}(s)=R_{i} \cdot F_{m} \cdot I_{o \phi} \cdot \operatorname{LPF}(s) \cdot G_{i}(s)
$$

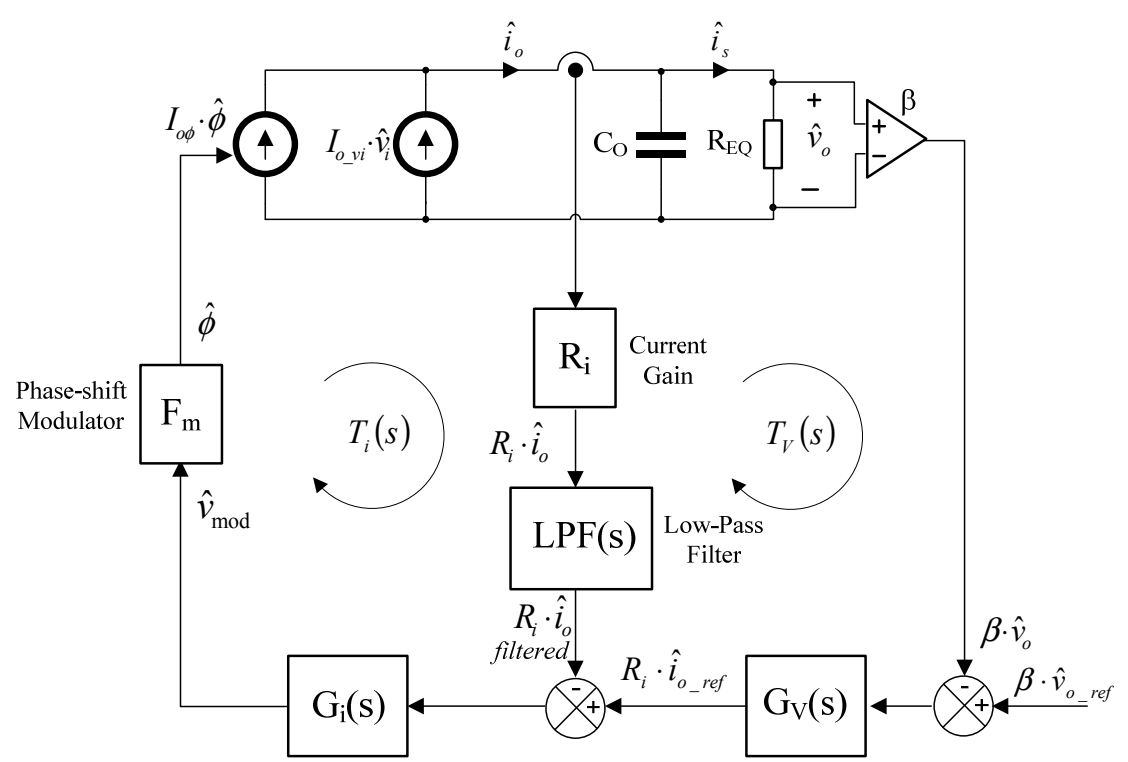

Figure 12. Small-signal model of a DAB with ACC when controlling the output current and voltage

After closing the current loop, the small-signal model of the voltage loop can be represented by means of the block diagram of figure 13, whose transfer functions of interest are summarized in table III. $\mathrm{I}_{\mathrm{O}_{-} \mathrm{CL}}(\mathrm{s})$ is the closed loop transfer function of the current loop. The current loop is designed with a crossover frequency considerably higher than that of the voltage loop: $f_{C I}>>f_{C V}$. Thus, seen from voltage loop the current loop can be simplified as a static gain: $\mathrm{I}_{\mathrm{O}_{\mathrm{CL}}}(\mathrm{s}) \approx \frac{1}{\mathrm{Ri}}$. It is worth pointing out that the poles of the $\operatorname{LPF}(\mathrm{s})$ are placed at frequencies much higher than $\mathrm{f}_{\mathrm{CI}}$, so that their effect is negligible at frequencies below $\mathrm{f}_{\mathrm{CI}}$. In figure $13, \mathrm{Z}(\mathrm{s})$ is the equivalent impedance of the parallel connection of $\mathrm{R}_{\mathrm{EQ}}$ and $\mathrm{C}_{\mathrm{O}}$, including the equivalent series resistance (ESR) of $\mathrm{Co}, R_{C}$. Thus, $\mathrm{Z}(\mathrm{s})$ is a transfer function with a low frequency pole and a high frequency zero.

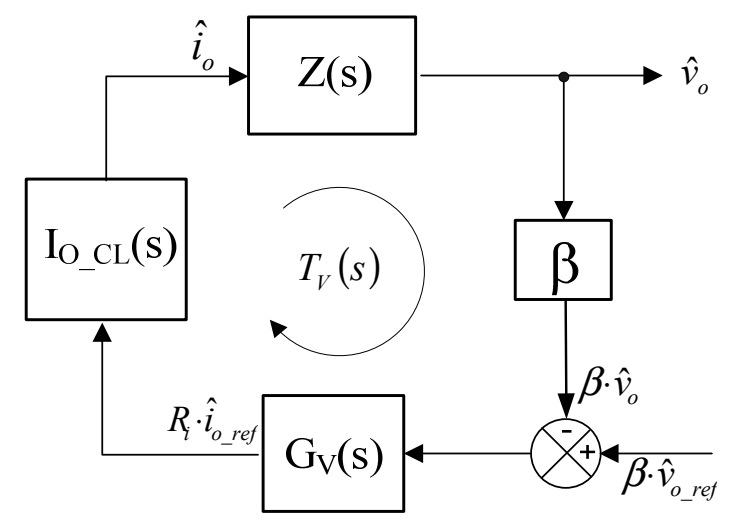

Figure 13. Block diagram of the voltage loop of the DAB with the current loop closed 
The loop gain of the voltage loop, $T_{V}(S)$, is described by (22). Its characteristics determine the speed and stability of the voltage loop. The controller $\mathrm{G}_{\mathrm{V}}(\mathrm{s})$ is designed so that $T_{V}(s)$ has a crossover frequency, $\mathrm{f}_{\mathrm{CV}}$, considerably lower than $\mathrm{f}_{\mathrm{CI}}$ at nominal power: $\mathrm{f}_{\mathrm{CV}} \approx \mathrm{f}_{\mathrm{CI} \text {-Pnom }} / 5$.

$$
T_{V}(s)=\beta \cdot Z(s) \cdot I_{O_{C L}}(s) \cdot G_{V}(s)
$$

In table IV the gains and transfer functions for the design of the current and voltage compensators, $\mathrm{G}_{\mathrm{i}}(\mathrm{s})$ and $\mathrm{G}_{\mathrm{V}}(\mathrm{s})$, are summarized. The design of the compensators for the $\mathrm{DAB}$ begins with the selection of the current and voltage sensor gains $R_{i}$ and $\beta$. The maximum crossover frequency of the current loop $\left(f_{C I}\right)$ is selected as: $f_{C I}=f_{s} / 5$. It is worth noting that the effective frequency of the output current in the DAB converter is twice the switching frequency $\left(\mathrm{f}_{\text {eff }}=2 \cdot \mathrm{f}_{\mathrm{s}}\right)$.

The poles of the LPF are selected to attenuate the high frequency ripple in the sensed current. The zero of the $G_{i}$ controller is chosen as: $\omega_{\mathrm{Z}}=\omega_{0}$. The gain $\omega_{\mathrm{i}}$ is adjusted to achieve a phase margin $(\mathrm{PM})>40^{\circ}$ and a gain margin $(\mathrm{GM})>6 \mathrm{~dB}$. In figure 14 the Bode plots of $T_{i}(s)$ for different values of the transferred power are depicted. For the nominal power the crossover frequency of the current loop is $\mathrm{f}_{\mathrm{CI}}=5.71 \mathrm{kHz}$ with a phase margin of $\mathrm{PM}=74.9^{\circ}$ and $\mathrm{GM}=19 \mathrm{~dB}$. The maximum crossover frequency occurs at $18.43 \mathrm{kHz}$, for $\mathrm{P}=0 \mathrm{~W}$. In the Bode plots of $\mathrm{I}_{\mathrm{O}_{-} \mathrm{CL}}(\mathrm{j} \omega)$ shown in Figure 15 it can be observed that the $\mathrm{DC}$ value of $\mathrm{I}_{\mathrm{O} \_\mathrm{CL}}(\mathrm{dB})$ has no variations with the power, taking the value: $1 / \mathrm{R}_{\mathrm{i}}$.

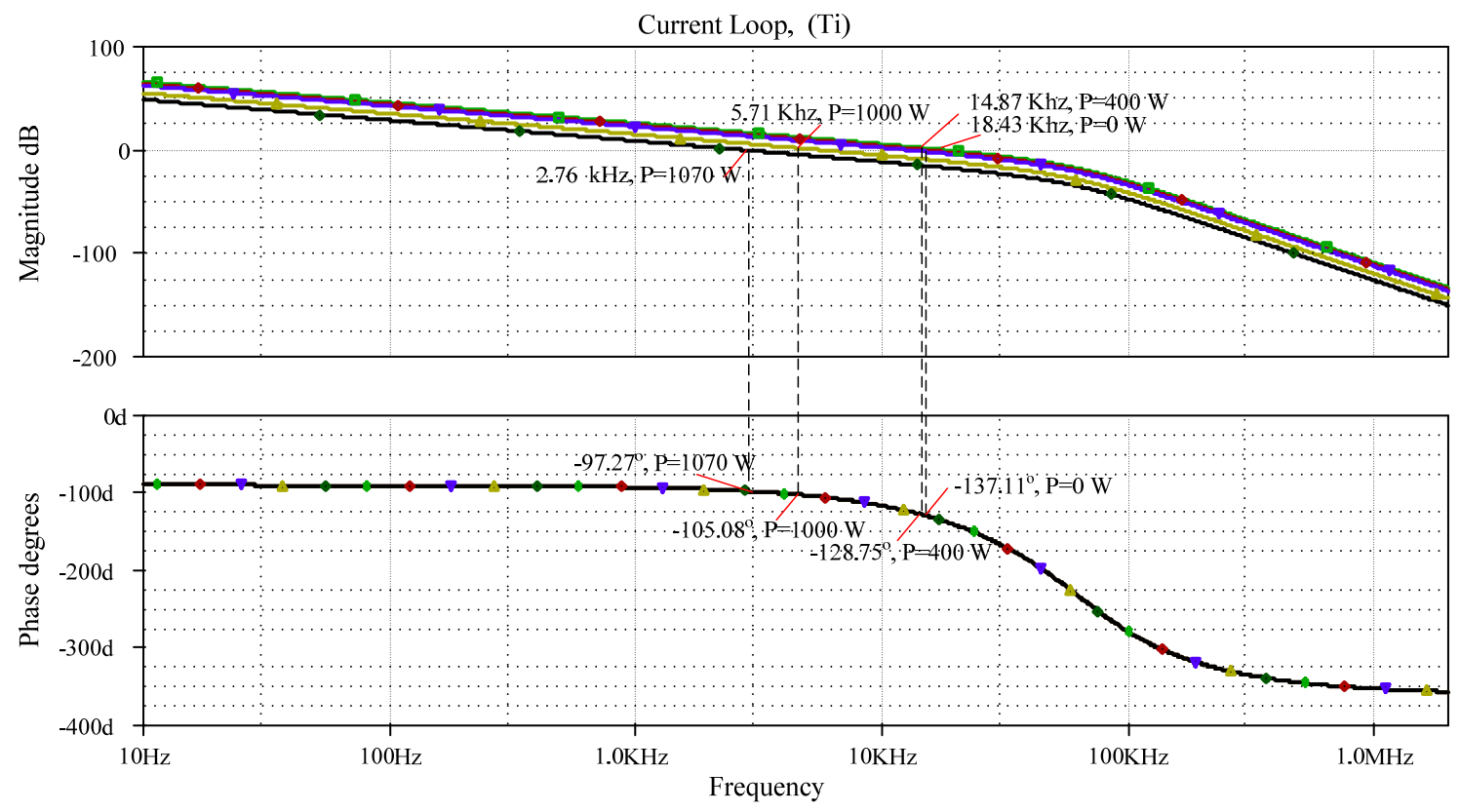

Figure 14. Bode plots of $T_{i}(j \omega)$ for different values of the transferred power: $\mathrm{Po}=[0,400 \mathrm{~W}, 600 \mathrm{~W}, 1000 \mathrm{~W}, 1070 \mathrm{~W}], \mathrm{Vi}=24 \mathrm{~V} . \mathrm{V}_{\mathrm{O}}=400 \mathrm{~V}$ 

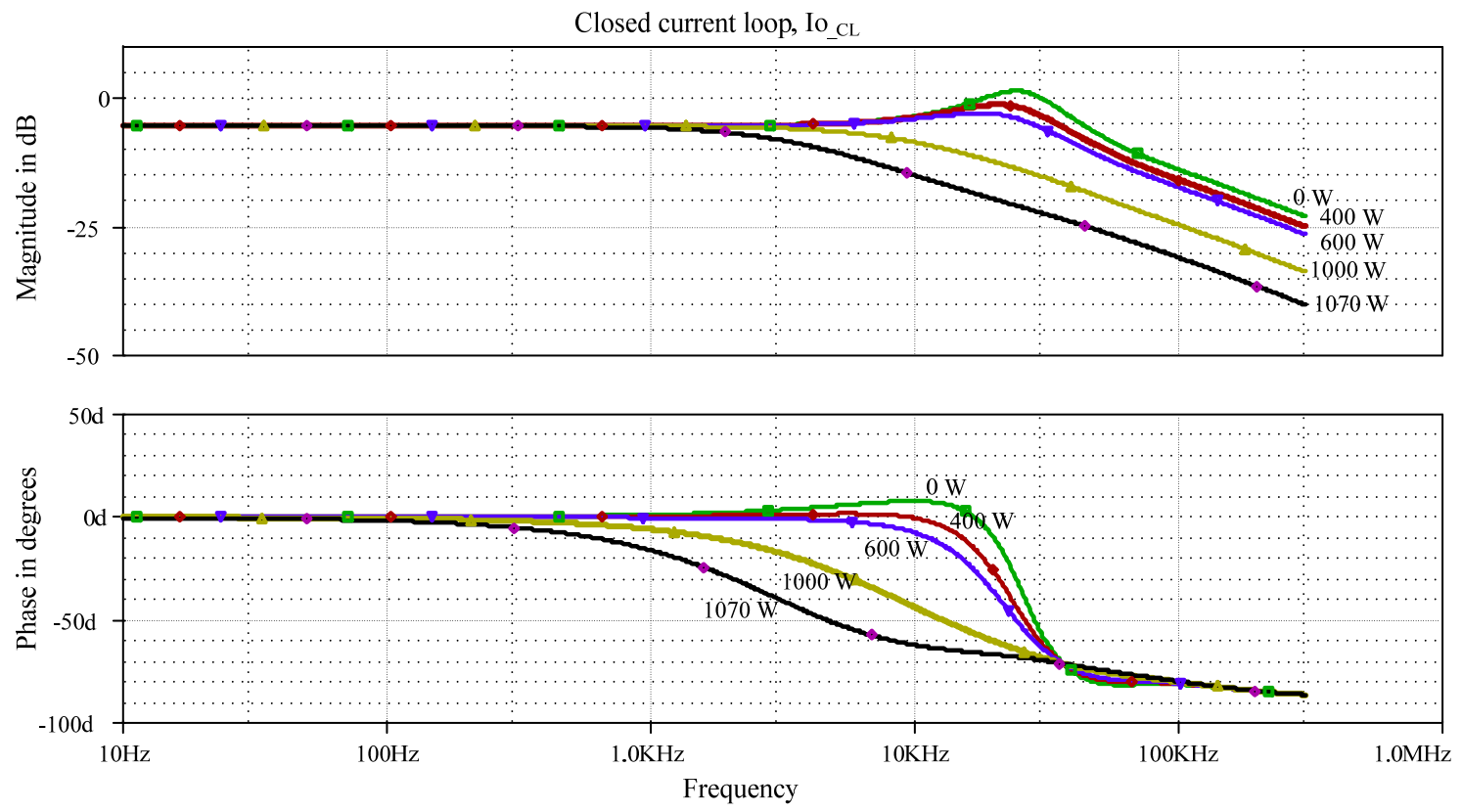

Figure 15. Bode plots of $\mathrm{I}_{\mathrm{O}_{-} \mathrm{CL}}(\mathrm{j} \omega)$ for different values of the transferred power:

$\mathrm{Po}=[0,400 \mathrm{~W}, 600 \mathrm{~W}, 1000 \mathrm{~W}, 1070 \mathrm{~W}], \mathrm{Vi}=24 \mathrm{~V} . \mathrm{V}_{\mathrm{O}}=400 \mathrm{~V}$

The Bode plots of the loop gain of the voltage loop, $\mathrm{T}_{\mathrm{V}}(\mathrm{s})$, are depicted in figure 16. It is observed that the crossover frequency values decrease with Po, ranging $f_{C V}$ from 1100 $\mathrm{Hz}(0 \mathrm{~W})$ to $987 \mathrm{~Hz}(1070 \mathrm{~W})$. The phase margin is $\mathrm{PM}=72.8^{\circ}$ at nominal power $(1000 \mathrm{~W})$ with $\mathrm{f}_{\mathrm{CV}}=1075 \mathrm{~Hz}$. The Bode plots of the voltage loop transfer function in closed loop are depicted in figure 17. The closed loop behavior under load changes (power changes) is stable for all the cases.
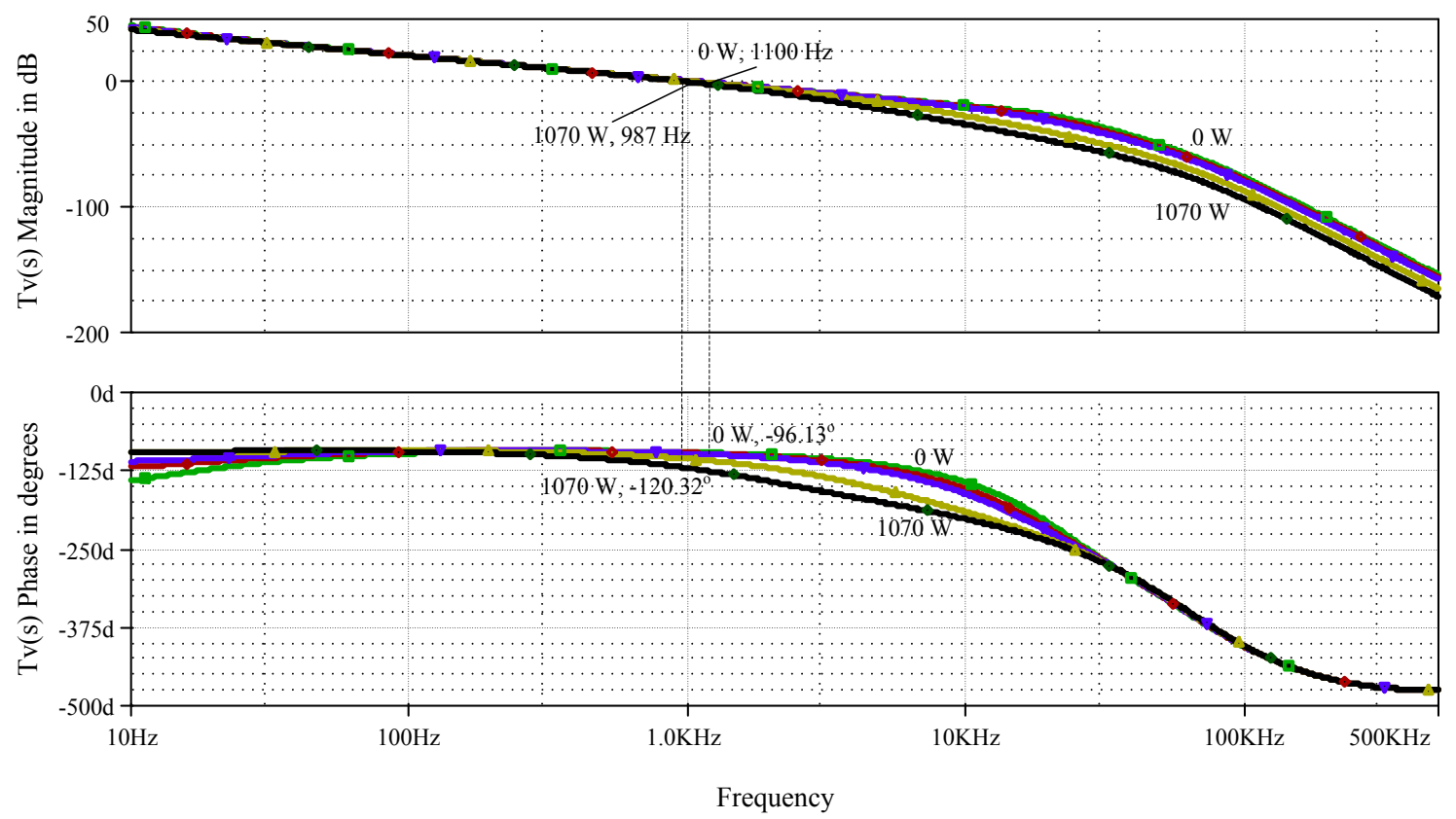

Figure 16. Bode plots of $\mathrm{T}_{\mathrm{V}}(\mathrm{j} \omega)$ for different values of the transferred power: $\mathrm{Po}=[0,400 \mathrm{~W}, 600 \mathrm{~W}, 1000 \mathrm{~W}, 1070 \mathrm{~W}], \mathrm{Vi}=24 \mathrm{~V} . \mathrm{V}_{\mathrm{O}}=400 \mathrm{~V}$ 

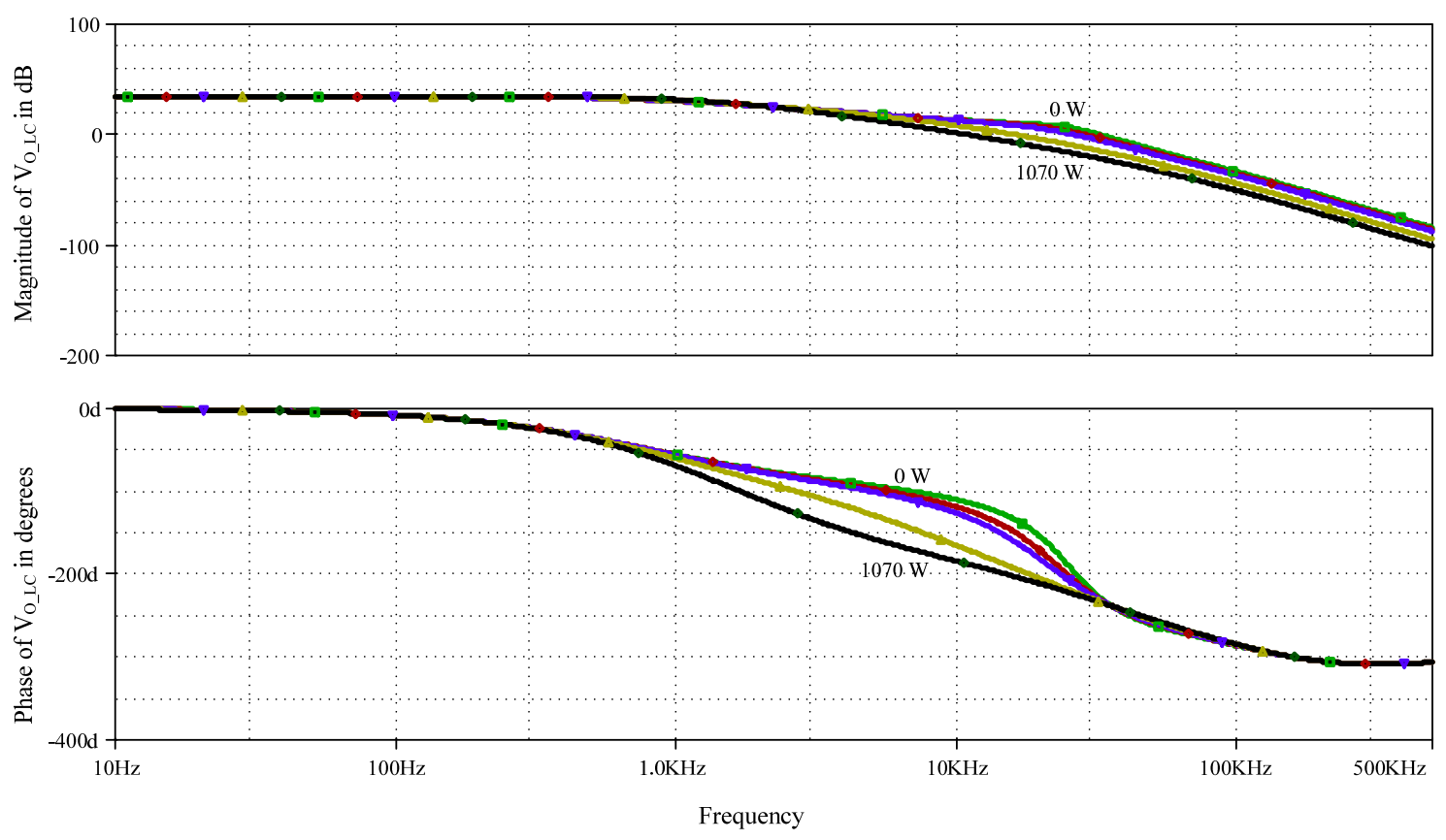

Figure 17. Bode plots of $\mathrm{V}_{\mathrm{O}_{-} \mathrm{LC}}(\mathrm{j} \omega)$ for different values of the transferred power: Po $=[0,400 \mathrm{~W}, 600 \mathrm{~W}, 1000 \mathrm{~W}, 1070 \mathrm{~W}], \mathrm{Vi}=24 \mathrm{~V} . \mathrm{V}_{\mathrm{O}}=400 \mathrm{~V}$

The sensitivity of the output voltage to load current variations is defined as the closed loop output impedance, $\mathrm{Z}_{\mathrm{O}_{-} \mathrm{CL}}$, in (23), where $\hat{\imath}_{g}(s)$ represents the load current perturbations. Figure 18 depicts the Bode plot (gain, $\mathrm{dB}$ ) of the output impedance of the $\mathrm{DAB}$. The maximum value of $\mathrm{Z}_{\mathrm{O}_{-} \mathrm{CL}}$ is $6.86 \mathrm{~dB}$, corresponding to a value of $2.2 \Omega$

$$
Z_{O_{-} C L}=\left.\frac{\hat{v}_{o}(s)}{\hat{\imath}_{g}(s)}\right|_{\hat{v}_{i}=0}
$$

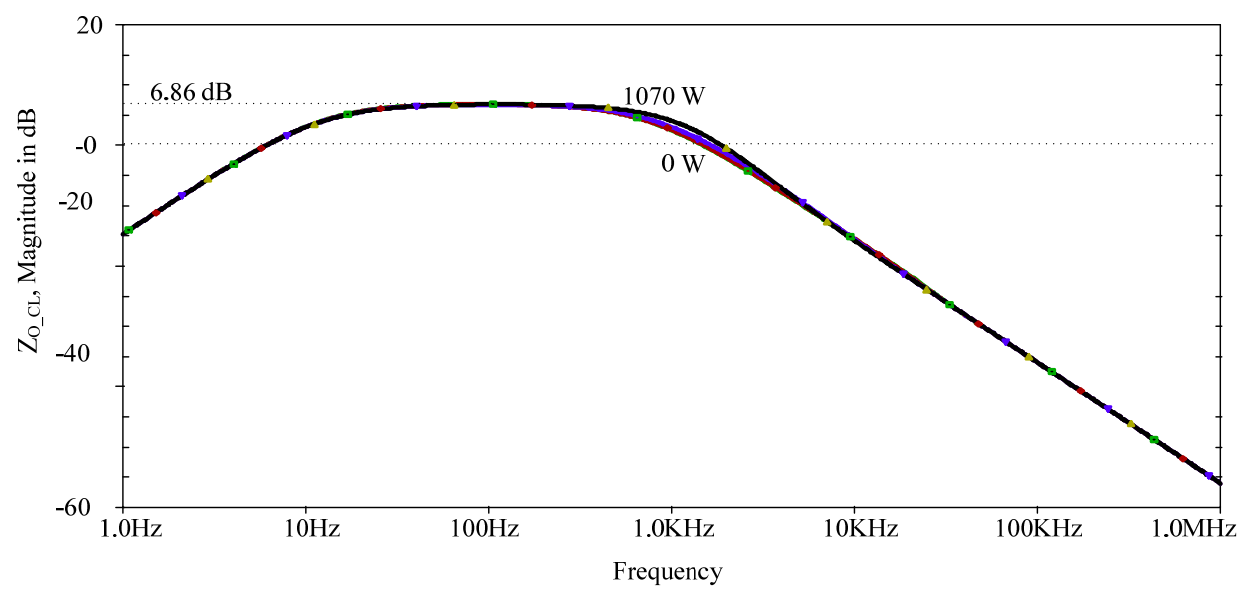

Figure 18. Bode plots of $\mathrm{Z}_{\mathrm{O} \_\mathrm{CL}}(\mathrm{j} \omega)$ for different values of the transferred power: $\mathrm{Po}=[0,400 \mathrm{~W}, 600 \mathrm{~W}, 1000 \mathrm{~W}, 1070 \mathrm{~W}] . \mathrm{Vi}=24 \mathrm{~V} . \mathrm{V}_{\mathrm{O}}=400 \mathrm{~V}$.

The transfer function of the closed loop sensitivity of the output voltage to input voltage variations, or closed loop audiosusceptibility, is defined by (24). The Bode plot (gain, 
$\mathrm{dB})$ of $\mathrm{A}_{\mathrm{CL}}(\mathrm{s})$ is depicted in figure 19. The magnitude increases with the transferred power: the maximum value at $860 \mathrm{~Hz}$ is $-23.84 \mathrm{~dB}$, i.e., 0.064 in a linear scale.

$$
A_{-} C L(s)=\left.\frac{\hat{v}_{o}(s)}{\hat{v}_{i}(s)}\right|_{\hat{\imath}_{g}(s)=0}
$$

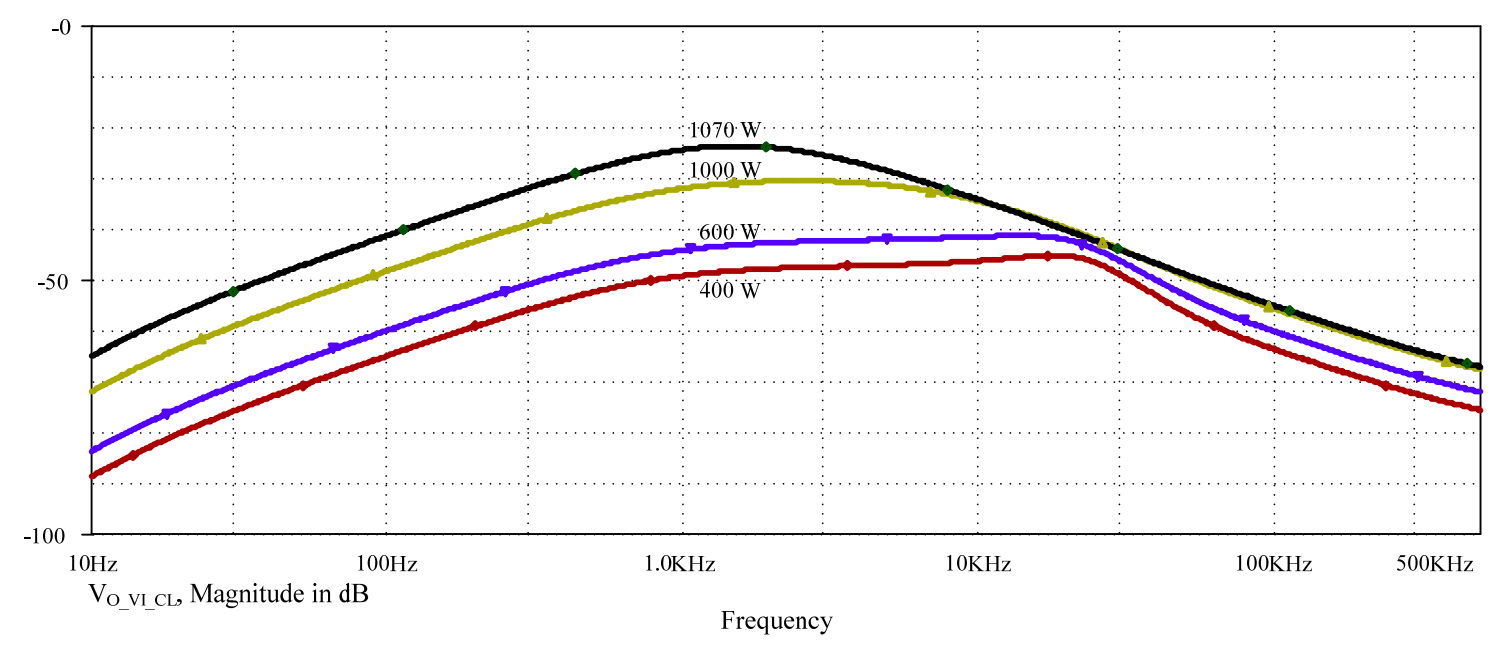

Figure 19. Bode plots of $A_{C L}(j \omega)$ (gain, $\left.d B\right)$ for different values of the output power. $\mathrm{Po}=[400 \mathrm{~W}, 600 \mathrm{~W}, 1000 \mathrm{~W}, 1070 \mathrm{~W}], \mathrm{Vi}=24 \mathrm{~V} . \mathrm{V}_{\mathrm{O}}=400 \mathrm{~V}$.

\section{LOAD-CURRENT FEED-FORWARD (LCFF) COMBINED WITH CURRENT MODE CONTROL}

The dynamic of the output voltage of the DAB under voltage reference changes or load changes can be improved by means of the load-current feed-forward ( $L C F F$ ) control $[22,26,27]$. Reference [27] deals with the general application of LCFF to current mode controlled DC-DC converters in order to improve the response of the output voltage to dynamic load variations. Nevertheless, to the authors' knowledge LCFF hasn't ever been applied to current mode controlled DAB converters. In [23] LCFF was applied to DABs with digital voltage mode control, having used a lookup table to compensate the load current disturbances. Another recent work [28] uses the feed-forward of the load current in a voltage controlled DAB to increase the magnitude of the loop gain at twice the grid frequency. That DAB converter was used in a multistage configuration as the input stage of an inverter.

The LCFF proposed in this paper is combined with current mode control to take advantage of the current protection feature of ACC. The proposed LCFF consists of an additional (load) current loop between the voltage loop and the inner current control loop. The goal of adding the feed-forward of the output current is to reduce the output impedance of the converter. With LCFF the output voltage transient under load changes is reduced both in magnitude and duration, so that the size and cost of the output capacitors can be reduced.

Figure 20 shows the scheme of an analog ACC controlled DAB with LCFF. In this case the output current, $I_{s}$, is sensed and added to the output of the voltage controller through 
a gain $\mathrm{R}_{\mathrm{FF}}$ (feed-forward gain). $v c^{\prime}$ is the variable that is fed-forward proportionally to the load current, whereas $u$ is the output of the voltage controller. $v c$ results from adding $u$ to $v c^{\prime}$, as expressed by (25).

$$
v c=u+v c^{\prime}=u+R_{F F} \cdot i_{S}
$$

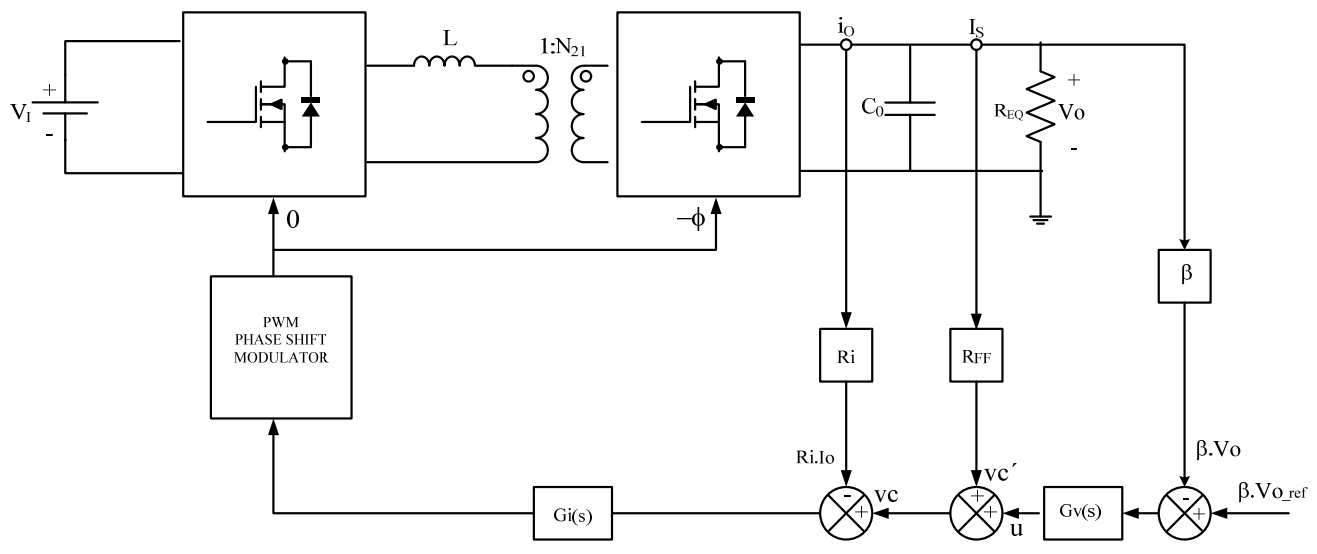

Figure 20. Control scheme of a DAB converter with ACC and load current feedforward.

In steady state, the main goal of the LCFF is that most of the current loop reference $(v c)$ comes from the load current feed-forward. Thus, only a small part of the current reference depends on the slower voltage controller. Under a load transient, the current reference depends strongly on the fast load feed-forward signal, $v c^{\prime}$. In steady-state the average value of the current through capacitor Co is 0 , so that $I_{S}=I_{o}$. As in steady-state: $v c=R_{i} \cdot I_{o}$ (due to the regulation of the current loop) and $v c^{\prime}=R_{F F} \cdot I_{S}=R_{F F} \cdot I_{o}$, the choice of $\mathrm{R}_{\mathrm{FF}}=\mathrm{R}_{\mathrm{i}}$ makes that $v c=v c$ ', so that $\mathrm{u} \approx 0$ in steady state. Thus, the natural choice of the feed-forward gain is: $\mathrm{R}_{\mathrm{FF}}=\mathrm{R}_{\mathrm{i}}$.

The small-signal model of the DAB can be represented by means of the block scheme depicted in figure 21, where several transfer functions of interest are identified and defined in Table V. The small-signal stability conditions for the choice of the value of $\mathrm{R}_{\mathrm{FF}}$ are obtained by means of the transfer function of the modified ACC power stage: from the output of the voltage regulator $u$ to output voltage vo, $\operatorname{Vou}(S) .{\widehat{\iota_{R}}}_{\text {dist }}$ represents the output current disturbance. 


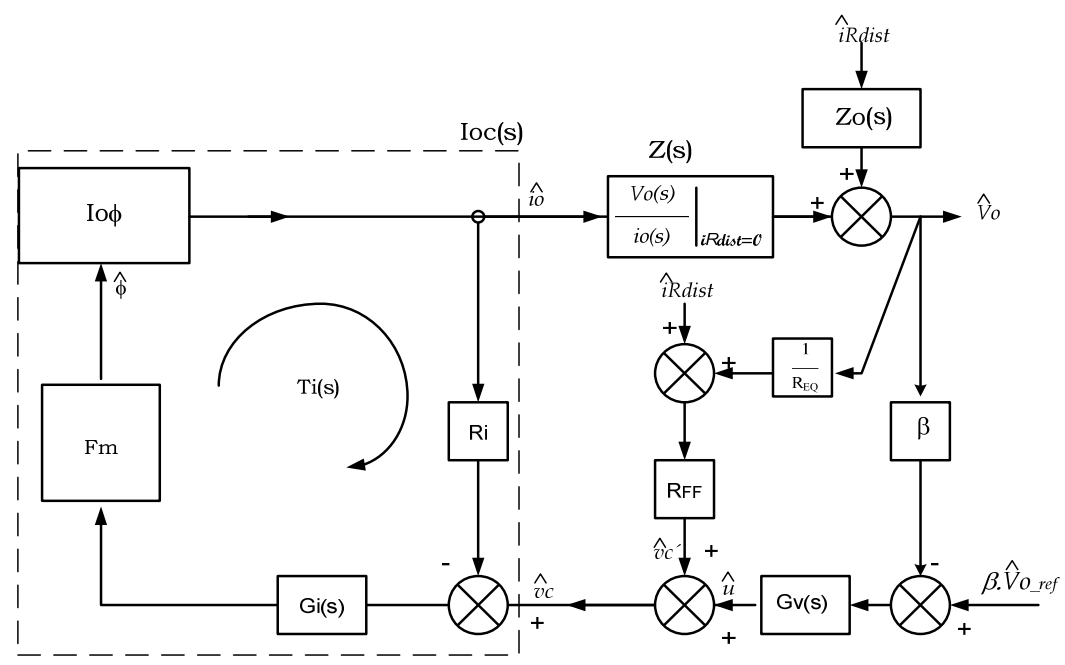

Figure 21. Small-signal model of a DAB with ACC and load current feed-forward

After closing the inner current loop and considering the output impedance Z(s) defined in table III, the LCFF working in closed loop can be represented by means of figure 22. The positive feedback signal of the LCFF can be expressed by (26).

$$
\hat{v} c^{\prime}=R_{F F} \cdot I_{R}=R_{F F} \cdot\left(\widehat{l}_{R} \text { dist }+\frac{\widehat{v_{0}}}{R_{E Q}}\right)
$$

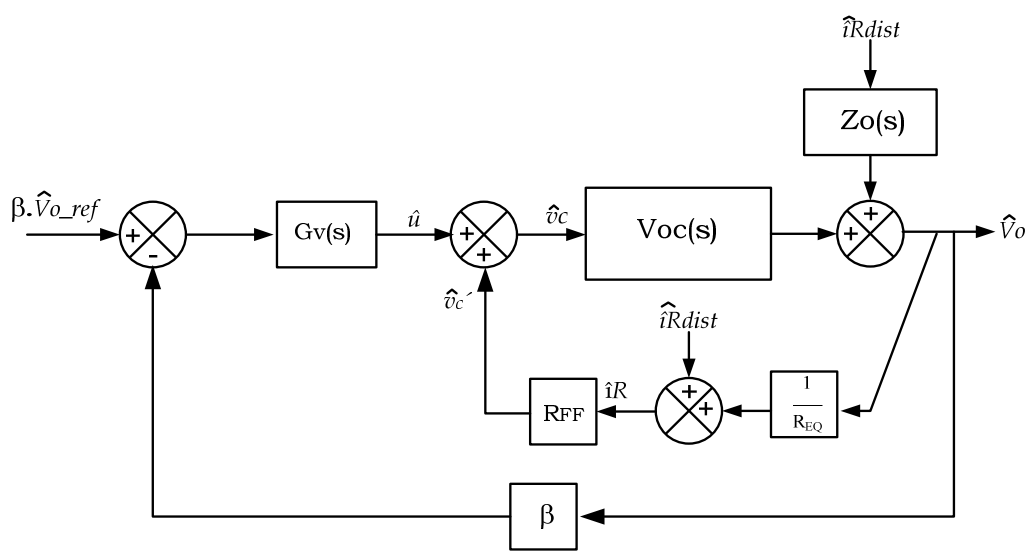

Figure 22. Equivalent block diagram of the voltage loop using $\mathrm{LCFF}+\mathrm{ACC}$ in a DAB converter

Making $\widehat{\imath}_{R}$ dist $=0$ in the simplified scheme of figure 22, $\operatorname{Vou}(s)$ results in a first order transfer function. At low frequency $|\operatorname{Ti}(\mathrm{s})|>>1$ and the zero $\omega_{z_{z} z}$ is located at a higher frequency than the pole $\omega_{p_{-} z}$. Thus, $\operatorname{Voc}(s)$ can be approximated by (27). Replacing (27) in the transfer function $\operatorname{Vou}(S)$ defined in table $\mathrm{V}$, the approximation (28) is obtained. $\operatorname{Vou}(s)$ is an open loop stable transfer function if $\omega p_{o u}>0$. Defining $\omega p_{o u}$ as: $\omega p_{o u}=\omega p_{o c} \cdot\left(1-K o c \cdot R_{F F} / R_{E Q}\right)$ and $K o u=K o c /\left(1-K o c \cdot R_{F F} / R_{E Q}\right)$ the stability condition of $\operatorname{Vou}(\mathrm{s})$ can be expressed by (29).

$$
\operatorname{Voc}(s)=\frac{R_{E Q}}{R i} \cdot \frac{1+\frac{s}{\omega Z_{\_} Z}}{1+\frac{S}{\omega p_{-} z}} \approx \frac{\frac{R_{E Q}}{R i}}{1+\omega p_{z}}=\frac{K o c}{1+\frac{S}{\omega p_{O C}}}
$$




$$
\begin{gathered}
\operatorname{Vou}(s) \approx \frac{K o c}{\left(1-K o c \cdot \frac{R_{F F}}{R_{E Q}}\right)+\frac{s}{\omega p_{o c}}}=\frac{K o u}{1+\frac{S}{\omega p_{o u}}} \\
R_{F F}<\frac{R_{E Q}}{K o c}
\end{gathered}
$$

As the same factor $\left(1-K o c \cdot R_{F F} / R_{E Q}\right)$ affects both $K o u$ and $\omega p_{o u}, \operatorname{Voc}(s)$ and $\operatorname{Vou}(s)$ agree in the low and medium frequency range. Thus, the same controller $G_{V}(s)$ can be used for ACC and LCFF control if the desired crossover frequency of the voltage loop is in the frequency range where $\operatorname{Voc}(s)$ and $\operatorname{Vou}(s)$ agree. From (27), Koc is identified as: $K o c=$ $\mathrm{R}_{\mathrm{EQ}} / \mathrm{Ri}$. Replacing this expression in (29) yields the stability condition: $\mathrm{R}_{\mathrm{FF}}<\mathrm{Ri}$. The stability condition of the LCFF of the DAB converter with ACC does not depend on the power level transferred to the load. Therefore, the implementation of LCFF+ACC in the $\mathrm{DAB}$ is easy and depends only on the gain of the current sensor being used.

$Z o(s)$ is the open loop output impedance with conventional ACC. The output impedance with $\mathrm{LCFF}+\mathrm{ACC}, Z o_{F F}(s)$ is defined by (30). From figure 22, if $\hat{u}=0, \hat{v}_{0}(s)$ can be expressed by (31). Solving for the open loop output impedance with feed forward, $\mathrm{Zo}_{\mathrm{FF}}$, it results (32).

$$
\begin{gathered}
Z o_{F F}(s)=\left.\frac{\widehat{v_{0}}(s)}{\hat{\imath}_{R d i s t}(\mathrm{~s})}\right|_{\widehat{u}=0} \\
\left.\widehat{v_{0}}(s)\right|_{\hat{u}=0}=\hat{\imath}_{R d i s t}(s) \cdot Z o(s)+\left(\frac{\hat{v}_{0}}{R_{E Q}}+\hat{\imath}_{R d i s t}(s)\right) \cdot R_{F F} \cdot \operatorname{Voc}(s) \\
Z o_{F F}(s)=\frac{Z o(s)+R_{F F} \cdot \operatorname{Voc}(s)}{1-\frac{R_{F F}}{R_{E Q}} \cdot \operatorname{Voc}(s)}
\end{gathered}
$$

The study of the closed loop output impedance of the DAB with LCFF+ACC can be carried out with the help of figure 23 and (32). The Bode plots (gain, $\mathrm{dB}$ ) of the closed loop output impedances $\mathrm{Zo}_{\mathrm{CL}}$ (ACC without LCFF) and $\mathrm{Zo}_{\mathrm{FFCL}}$ (ACC with LCFF) expressed by (33) and (34), respectively, are depicted in figure 24. It is observed that LCFF achieves an important output impedance reduction, more than $20 \mathrm{~dB}$ at low frequency.

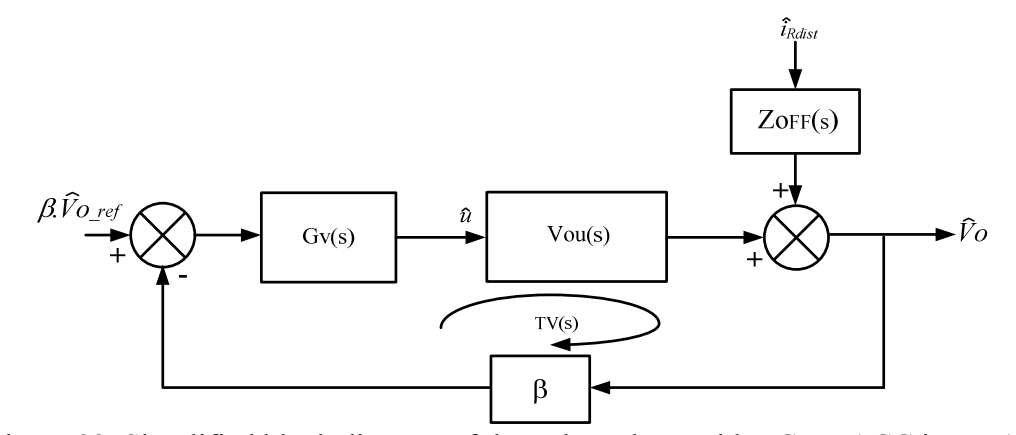

Figure 23. Simplified block diagram of the voltage loop with LCFF+ACC in a DAB 


$$
\begin{gathered}
Z o_{C L}(s)=\left.\frac{\widehat{v_{0}}(s)}{\hat{\imath}_{\text {Rdist }}(\mathrm{s})}\right|_{\widehat{u} \neq 0}=\frac{Z o(s)}{1+T v(s)} \\
Z o_{F F C L}(s)=\left.\frac{\widehat{v_{0}}(s)}{\hat{\imath}_{\text {Rdist }}(\mathrm{s})}\right|_{\widehat{u} \neq 0}=\frac{Z o_{F F}(s)}{1+\operatorname{Tv}(s)}
\end{gathered}
$$

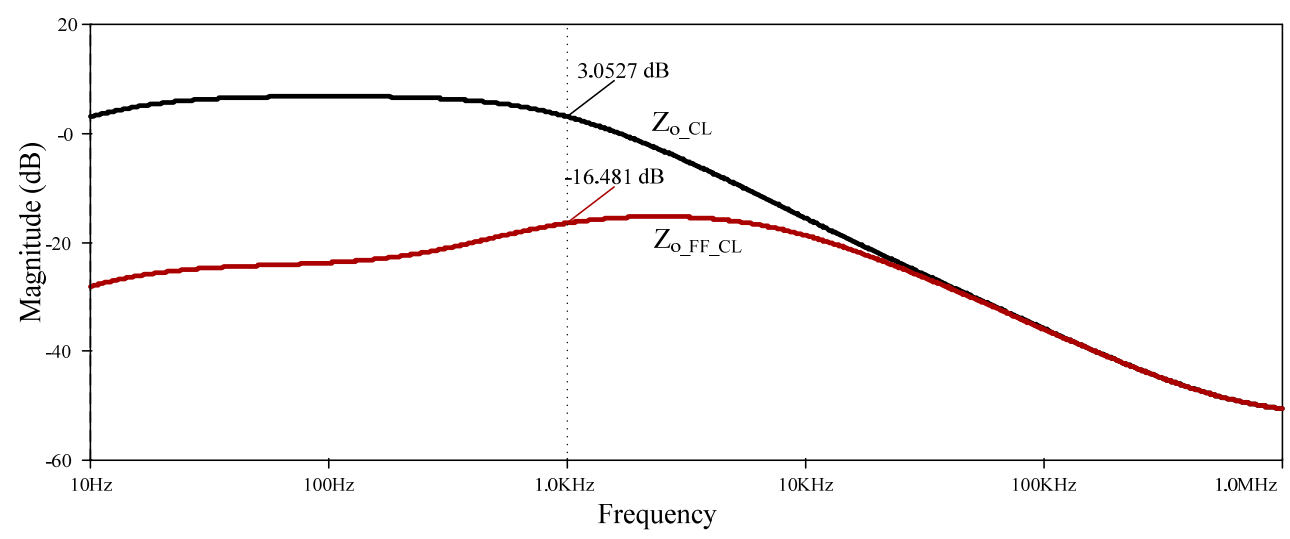

Figure 24. Closed loop output impedance $(\mathrm{dB})$ with and without $\mathrm{LCFF}, \mathrm{Z}_{\mathrm{oFF}-\mathrm{CL}}$ and $\mathrm{Z}_{\mathrm{o} \_\mathrm{CL}}$, respectively. Operation point: $\mathrm{P}=1 \mathrm{~kW}, \mathrm{Vi}=24 \mathrm{~V}$, and $\mathrm{Vo}=400 \mathrm{~V}$. The gain values $(\mathrm{dB})$ are indicated at $\mathrm{f}=1 \mathrm{kHz}$

\section{Simulations AND EXPERIMENTAL RESUltS}

The DAB converter and the proposed controllers were simulated by means of PSIM ${ }^{\circledR}$ simulation software. The parameters of the DAB converter were summarized in table I, whereas the values of the designed controllers are shown in table VI. Simulation waveforms of the output voltage response to load steps from $200 \mathrm{~W}$ to $1 \mathrm{~kW}$ and back to $200 \mathrm{~W}$ with ACC and with LCFF+ACC are depicted in figure 25. The feed-forward gain $R_{F F}$ is $90 \%$ of the current sensor gain $R i\left(R_{F F}=1.65 \Omega\right)$. Without LCFF the output voltage is stable and well damped. However, it is observed a much faster response offered by the inclusion of the LCFF under the same conditions. The voltage deviation during the transient is much lower with LCFF. This control strategy solves the slow response obtained by the use of a cascaded current and voltage control structure with PI controllers typical from ACC. 

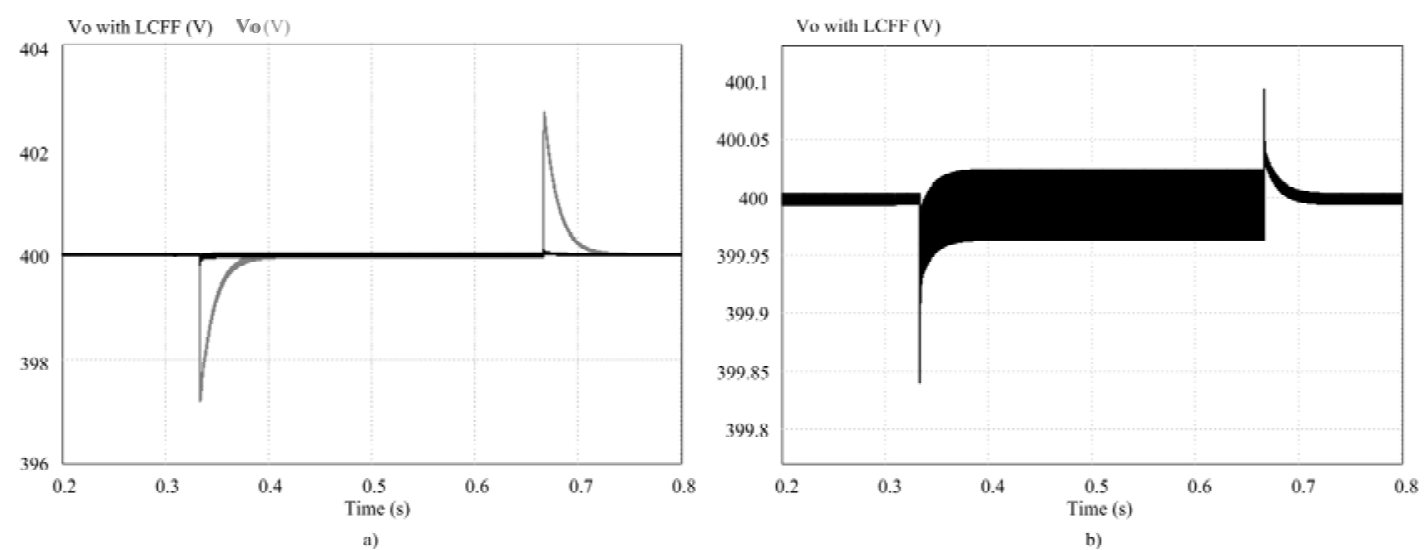

Figure 25. Simulation waveforms of the output voltage of the DAB

a) Output voltage response of the DAB converter with and without LCFF to load steps from $200 \mathrm{~W}$ to $1 \mathrm{~kW}$ and back to $200 \mathrm{~W}$. b) Detail of the dynamic response of the DAB converter with LCFF.

A prototype of the simulated $1 \mathrm{~kW}$ DAB has been built and tested. The designed controllers were implemented analogically using the UC3875 phase-shift controller and some TL084 operational amplifiers for both the current and the voltage loops. To measure the output currents small shunts are used. Figure 26 depicts the $1 \mathrm{~kW}$ prototype.

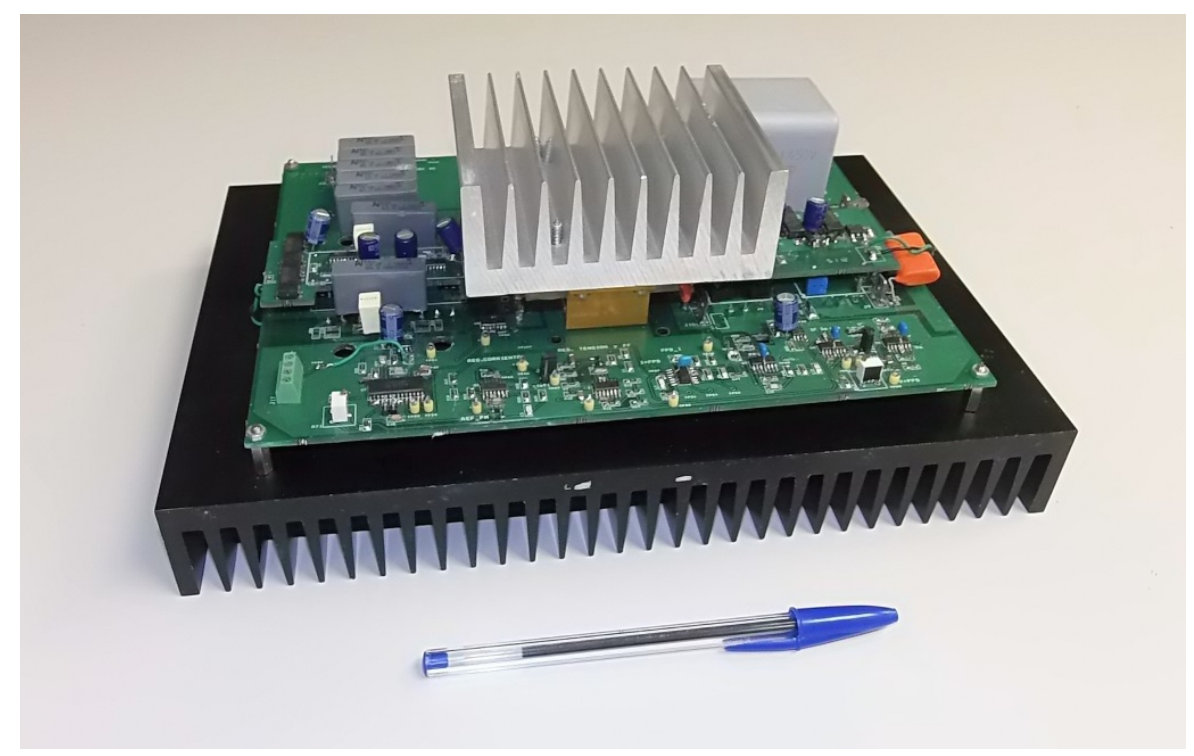

Figure 26. Photograph of the $1 \mathrm{~kW}$ DAB prototype

The dynamic behavior of the DAB converter has been tested by applying load step changes from $200 \mathrm{~W}$ to $800 \mathrm{~W}$ and back to $200 \mathrm{~W}$. The first test has been performed to the DAB converter with ACC. The resulting waveforms are shown in figure 27 . It can be observed from figure 27 that the dynamic response of the output voltage is stable and well damped.

The test results of the DAB converter with $\mathrm{LCFF}+\mathrm{ACC}$ under the same load steps are shown in figure 28. It is observed that the slow dynamic response of the DAB with ACC is substantially improved when LCFF is introduced. Without feed-forward, the peak deviation of the output voltage for load current steps from $0.5 \mathrm{~A}$ to $2 \mathrm{~A}$ is about 
$10 \mathrm{~V}(2.5 \%)$, and it takes around $50 \mathrm{~ms}$ to the voltage to return to the reference value. With LCFF+ACC, both the peak deviation and the duration of the transient are difficult to read accurately because they are very small. The peak deviation is about $2 \mathrm{~V}(0.5 \%)$ and the transient duration around $1 \mathrm{~ms}$. LCFF has reduced the magnitude of the transient deviation by a factor of $10 \mathrm{~V} / 2 \mathrm{~V}=5$, and the duration of the transient by a factor of about $50 \mathrm{~ms} / 1 \mathrm{~ms}=50$. It is worth noting that the addition of LCFF to ACC implies just a few additional and inexpensive components.

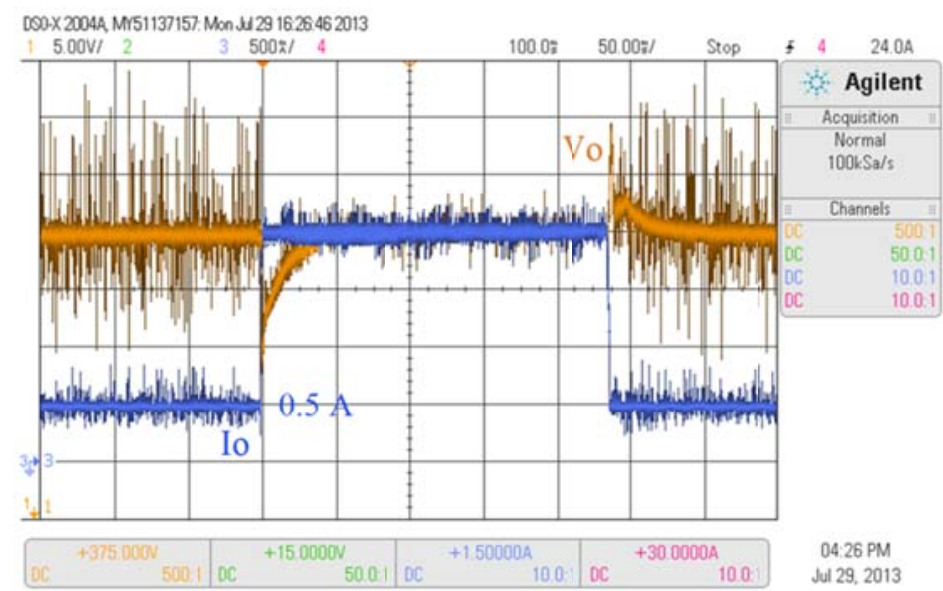

Figure 27. Dynamic response of the DAB converter with ACC to load steps ranging from $200 \mathrm{~W}$ to $800 \mathrm{~W}$ and back to $200 \mathrm{~W}$. Scales: Vo (5 V/div), Io (500 mA/div) and time scale $(50 \mathrm{~ms} / \mathrm{div})$

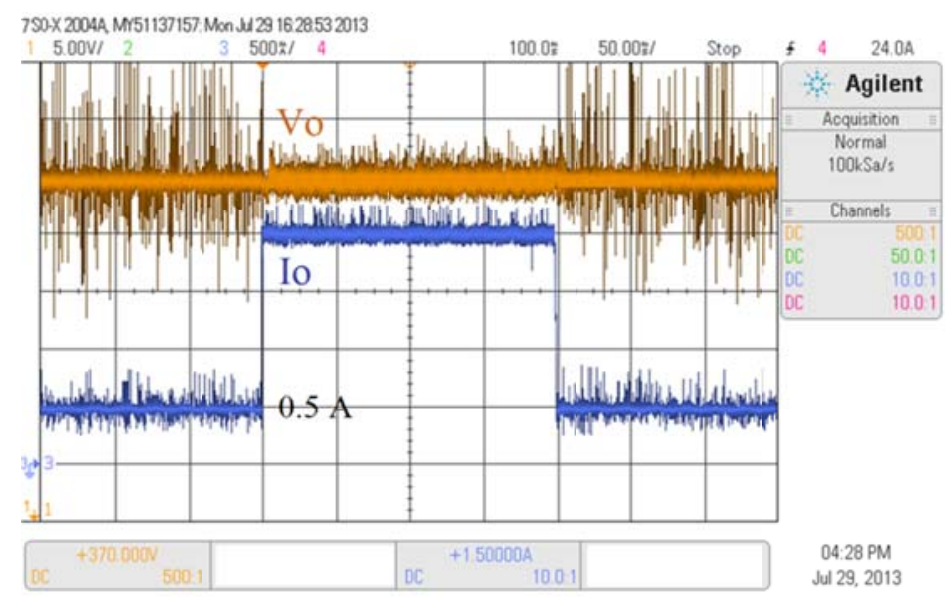

Figure 28. Dynamic response of the DAB converter with LCFF+ACC to load steps ranging from $200 \mathrm{~W}$ to $800 \mathrm{~W}$ and back to $200 \mathrm{~W}$. Scales: Vo (5 V/div), Io (500 mA/div) and time scale (50 ms/div).

\section{CONCLUSION}

The DAB converter is a bidirectional topology that offers isolation, high power density and efficiency. Several studies of DABs applied to solid-state transformer (SST) systems include a feed-forward path control to enhance the converter behavior [23], [28]. None of those studies provides the overcurrent protection inherent to current mode control, because they use a simple voltage mode control scheme. 
In this paper Average Current mode Control (ACC) is applied to the control of the DAB based on a small-signal model. The relatively slow dynamic response of the voltage loop is compensated by means of load current feed-forward (LCFF), which drastically improves the response of the output voltage to load steps. The converter response under load variations is fast and stable.

An adjustment procedure of ACC and LCFF+ACC for the DAB converter has been explained, along with stability criteria for the choice of the LCFF gain. Simulation and experimental results on a $1 \mathrm{~kW}$ DAB converter confirm the performance of both control strategies. The response of the output voltage is fast, stable and well damped at large load steps.

\section{ACKNOWLEDGEMENTS}

This work was supported by the Spanish Ministry of Economy and Competitiveness under grant ENE2012-37667-C02-01.

\section{REFERENCES}

1. Vazquez S, Lukic SM, Galvan E, Franquelo LG, and Carrasco JM, Energy Storage Systems for Transport and Grid Applications. IEEE Transactions on Industrial Electronics 2010; 57(12): 3881-3895.

2. De Doncker RW, Divan DM, Kheraluwala MH. A three-phase soft-switched high-power-density DC/DC converter for high-power applications. IEEE Transactions on Industry Applications 1991; 27(1): 63-73.

3. Kheraluwala MH, Gascoigne RW, Divan DM, Baumann ED. Performance characterization of a high-power dual active bridge DC-to-DC converter. IEEE Transactions on Industry Applications 1992; 28(6): 1294- 1301.

4. Chang Y-H, Wu K-W. A Gain/ Efficiency-enhanced Bidirectional Switchedcapacitor DC-DC Converter. International Journal of Circuit Theory and Applications 2014; 42(5): 468-493, DOI: 10.1002/cta.1863.

5. Li H, Liu D, Peng FZ, Gui-Jia S. Small Signal Analysis of A Dual Half Bridge Isolated ZVS Bi-directional DC-DC converter for Electrical Vehicle Applicat. 36th IEEE Power Electronics Specialists Conference 2005: 2777-2782.

6. Nguyen TV, Petit P, Aillerie M, Salame C., Charles J.-P. Efficiency of magnetic coupled boost DC-DC converters mainly dedicated to renewable energy systems: influence of the coupling factor. International Journal of Circuit Theory and Applications. Article published online: 4 Abril 2014. DOI: 10.1002/cta.1994

7. Chiu H-J, Yao C-J, Lo Y-K. A DC/DC converter topology for renewable energy systems. International Journal of Circuit Theory and Applications 2009; 37(3):485-495. DOI: 10.1002/cta.475

8. Chiu H-J, Lo Y-K, Kuo S-W, Cheng S-J, Lin F-T. Design and implementation of a high-efficiency bidirectional DC-DC Converter for DC micro-grid system applications. International Journal of Circuit Theory and Applications 2013. Article published online: 14 MAY 2013, DOI: 10.1002/cta.1910 
9. Doishita K, Hashiwaki M, Aoki T, Kawagoe Y, Murakami N. Highly reliable uninterruptible power supply using a bi-directional converter. The 21st International Telecommunication Energy Conference, Jun 1999. INTELEC '99. 1:5. DOI: 10.1109/INTLEC.1999.794066

10. Krismer F, Biela J, Kolar JW. A comparative evaluation of isolated bi-directional DC/DC converters with wide input and output voltage range. 40th IAS Annual Meeting Industry Applications Conference, 2005; 1: 599- 606

11. Aggeler D, Biela J, Inoue S, Akagi H, Kolar JW. Bi-Directional Isolated DC-DC Converter for Next-Generation Power Distribution - Comparison of Converters using Si and SiC Devices. Power Conversion Conference-Nago. 2007: 510-517.

12. Krishnamurthy HK, Ayyanar R. Building Block Converter Module for Universal (AC-DC, DC-AC, DC-DC) Fully Modular Power Conversion Architecture. IEEE Power Electronics Specialists Conference, 2007: 483-489.

13. Romero-Cadaval E, Spagnuolo G, Franquelo LG, Ramos-Paja CA, Suntio T, Xiao WM. Grid Connected Photovoltaic Generation Plants. Components and Operation. IEEE Industrial Electronics Magazine 2013, 7(3): 6-20.

14. Yu X, She X, Ni X, Huang AQ. System Integration and Hierarchical Power Management Strategy for a Solid-State Transformer Interfaced Microgrid System IEEE Transactions on Power Electronics 2014; 29(8): 4414-4425.

15. Liserre M, Sauter T, Hung JY, Future energy systems: integrating renewable energy sources into the smart power grid through industrial electronics. IEEE Industrial Electronics Magazine 2010; 4(1): 18-37.

16. Mi C, Bai H, Wang C, Gargies S. Operation, design and control of dual Hbridge-based isolated bidirectional DC-DC converter. IET Power Electronics 2008; 1(4): 507-517.

17. Friedemann A, Krismer F, Kolar JW. Design of a Minimum Weight Dual Active Bridge Converter for an Airborne Wind Turbine System. Proceedings of the 27th Applied Power Electronics Conference and Exposition (APEC 2012).

18. Middlebrook RD, Cuk S. A general unified approach to modelling switchingconverter power stages. IEEE PESC 1976; 1:18-30.

19. Krismer F, Kolar JW. Accurate Power Loss Model Derivation of a High-Current Dual Active Bridge Converter for an Automotive Application. IEEE Transactions on industrial electronics 2010; 57 (3): 881-891.

20. Qin H, Kimball JW. Generalized Average Modeling of Dual Active Bridge DCDC Converter. IEEE Transactions on Power Electronics 2012; 27(4): 2078-2084

21. Segaran D, McGrath B, Holmes DG. Adaptive dynamic control of a Bidirectional DC-DC converter. IEEE Proceedings Energy Conversion Congress, 2010: 14421449.

22. Bai H, Mi C, Wang C, Gargies S. The dynamic model and hybrid phase-shift control of a dual-active-bridge converter.Proceedings. IECON 2008:2840-2845.

23. Segaran D, Holmes DG, McGrath B. Enhanced Load Step Response for a Bidirectional DC-DC Converter. IEEE Transactions on power electronics 2013; 28(1): 371-379. 
24. Tang W, Lee FC, Ridley RB. Small-signal modeling of average current-mode control. APEC'92. Seventh Annual Conference Proceedings 1992:747,755.

25. Kheraluwala MH. High-Power High frequency DC-DC converters. PhD thesis, University of Wisconsin, Madison. 1991.

26. Fang C-C. Sampled-data poles, zeros, and modeling for current-mode control. International Journal of Circuit Theory and Applications 2013, 41: 111-127. DOI: $10.1002 /$ cta.790

27. Redl R, Sokal NO. Near-optimum dynamic regulation of DC-DC converters using feed-forward of output current and input voltage with current-mode control. IEEE Transactions on Power Electronics 1986, PEL-1(3): 181-192.

28. Qin H, Kimball JW. Closed-loop control of DC-DC dual active bridge converters driving single-phase inverters. IEEE Energy Conversion Congress and Exposition (ECCE), 2012: 173-179. 


\begin{tabular}{|c|c|}
\hline Parameter & Value \\
\hline Input Voltage, $\mathrm{V}_{\mathrm{i}}$ & $24 \mathrm{~V}$ \\
\hline Output Voltage, $\mathrm{V}_{\mathrm{O}}$ & $400 \mathrm{~V}$ \\
\hline Switching frequency $\left(\mathrm{f}_{\mathrm{s}}\right)$ & $100 \mathrm{kHz}$ \\
\hline Rated Power, $\mathrm{P}_{\mathrm{O}}$ & $1000 \mathrm{~W}$ \\
\hline $\mathrm{C}_{\mathrm{i}}$, Input capacitor & $100 \mu F$ \\
\hline $\mathrm{ESR}, \mathrm{R}_{\mathrm{Ci}}$ & $1 \mathrm{~m} \Omega$ \\
\hline $\mathrm{C}_{0}$, Output capacitor & $100 \mu F$ \\
\hline $\mathrm{ESR}, \mathrm{R}_{\mathrm{Co}}$ & $2.5 \mathrm{~m} \Omega$ \\
\hline Transformer Turns ratio, $\mathrm{N}_{21}$ & $30: 2$ \\
\hline Transformer leakage inductance (seen from HV side) & $6 \mu H$ \\
\hline External AC inductor (seen from HV side) & $159 \mu H$ \\
\hline Total AC inductance (External + Leakage), L & $165 \mu H$ \\
\hline Transformer magnetizing inductance (seen from HV side) & $5.13 \mathrm{mH}$ \\
\hline Input bridge Mosfets & IRFP3077PBF \\
\hline Output bridge Mosfets & $S P W 35 N 60 C F D$ \\
\hline
\end{tabular}


Table II. Open-loop transfer functions of the DAB converter playing a role in the control of the output variables $\left(\mathrm{v}_{\mathrm{o}}\right.$ and $\left.\mathrm{i}_{\mathrm{o}}\right)$

\begin{tabular}{c|c}
\hline Function and conditions & Expression \\
\hline \hline$G_{\mathrm{v}_{\phi}}(s)=\left.\frac{\hat{v}_{O}(s)}{\hat{\phi}(s)}\right|_{\widehat{\iota_{g}}=\widehat{v}_{l}=0}$ & $\mathrm{G}_{\mathrm{v}_{\phi}}(\mathrm{s})=\frac{V_{i}}{N_{21} \cdot 2 \pi \cdot f_{s} \cdot L} \cdot\left(1-\frac{2 \cdot|\Phi|}{\pi}\right) \cdot \frac{R_{E Q}}{1+s C R_{E Q}}$ \\
$A(s)=\left.\frac{\hat{v}_{O}(\mathrm{~s})}{\hat{v}_{i}(\mathrm{~s})}\right|_{\hat{\mathrm{I}}_{\mathrm{g}}=\widehat{\phi}=0}$ & $\mathrm{~A}(\mathrm{~s})=\frac{\Phi}{N_{21} \cdot 2 \pi \cdot f_{s} \cdot L} \cdot\left(1-\frac{|\Phi|}{\pi}\right) \cdot \frac{R_{E Q}}{1+s C R_{E Q}}$ \\
$Z_{O}=\frac{\hat{v}_{O}(\mathrm{~s})}{\left.\hat{I}_{g}(\mathrm{~s})\right|_{\widehat{\mathrm{v}}_{\mathrm{l}}=\widehat{\phi}=0}}$ & $\mathrm{Zo}(\mathrm{s})=\frac{R_{E Q}}{1+s C R_{E Q}}$ \\
\hline
\end{tabular}


Table III. Closed-loop transfer functions of the DAB converter with ACC for the control of the output current and voltage.

\begin{tabular}{c|c}
\hline Transfer Function & Expression \\
\hline \hline$I_{O_{-} C L}(s)=\frac{\hat{\imath}_{O}(s)}{R_{i} \cdot \hat{\imath}_{O_{-} r e f}(s)}$ & $I_{O_{-} C L}(s)=\frac{1}{R_{i} \cdot L P F(s)} \cdot \frac{T_{i}(s)}{1+T_{i}(s)}$ \\
\hline$Z(s)=R_{E Q} \|\left(R_{C}+\frac{1}{s \cdot C_{O}}\right)$ & $Z(s)=R_{E Q} \cdot \frac{1+\frac{s}{\omega_{z_{-} z}}}{1+\frac{s}{\omega_{p_{-} z}}}$ \\
\hline$V_{O_{-} C L}(s)=\frac{1}{\beta \cdot \hat{v}_{O_{-} r e f}(s)}$ & $\omega_{z_{-} z}=\frac{1}{R_{C} \cdot C_{O}} ; \omega_{p_{-} z}=\frac{1}{\left(R_{E Q}+R_{C}\right) \cdot C_{O}} \approx \frac{1}{R_{E Q} \cdot C_{O}}$ \\
\hline \hline
\end{tabular}


Table IV. Gains and transfer functions of the chosen controllers

\begin{tabular}{|c|c|}
\hline Name & Expression \\
\hline Current sensor gain, $R i$ & $1.85 \Omega$ \\
\hline Voltage sensor gain, $\beta$ & $18 \mathrm{~m} \Omega$ \\
\hline $\begin{array}{l}\text { Low pass filter } \\
\text { LPF(s) }\end{array}$ & $\begin{array}{l}L P F(s)=\frac{1}{1+\frac{s}{\omega_{o}}} \cdot \frac{\omega_{n}^{2}}{s^{2}+2 \cdot \zeta \cdot \omega_{n} \cdot s+\omega_{n}^{2}} \\
\zeta=\frac{1}{\sqrt{2}} \quad \omega_{o} \approx \frac{4 \pi \cdot f_{s}}{10} \quad \omega_{n}=\frac{4 \pi \cdot f_{s}}{3}\end{array}$ \\
\hline $\begin{array}{l}\text { Output current controller } \\
\qquad \mathrm{G}_{\mathrm{i}}(\mathrm{s})\end{array}$ & $\begin{array}{c}G_{i}(s)=\frac{\omega_{i}}{s} \cdot \frac{\left(1+\frac{s}{\omega_{Z}}\right)}{\left(1+\frac{s}{\omega_{p}}\right)} \\
\omega_{z}=\frac{4 \pi \cdot f_{s}}{10}, \quad \omega_{p}=\frac{4 \pi \cdot f_{s}}{5}, \quad \omega_{i}=\frac{4 \pi^{2} \cdot f_{C i \_ \text {max }} \cdot f_{s} \cdot N_{21} \cdot L}{V_{i} \cdot R_{i} \cdot F_{m}}\end{array}$ \\
\hline $\begin{array}{l}\text { Output Voltage Controller } \\
\qquad \mathrm{G}_{\mathrm{V}}(\mathrm{s})\end{array}$ & $\begin{array}{c}G_{V}(s)=\frac{\omega_{i V}}{s} \cdot \frac{\left(1+\frac{s}{\omega_{Z V}}\right)}{\left(1+\frac{s}{\omega_{P V}}\right)} \\
\omega_{z V}=\frac{1.1 P_{\max }}{V_{0}^{2} \cdot C_{0}} \quad \omega_{p V}=\frac{4 \pi \cdot f_{s}}{2}\end{array}$ \\
\hline
\end{tabular}


Table V. Transfer functions of the DAB with ACC and LCFF.

\begin{tabular}{|c|c|}
\hline Definition & Expression \\
\hline $\operatorname{Ioc}(s)=\frac{\widehat{\iota_{0}}(s)}{\widehat{v_{c}}(s)}$ & $\operatorname{Ioc}(s)=\frac{1}{R i} \cdot \frac{T i(s)}{1+T i(s)}$ \\
\hline $\operatorname{Voc}(s)=\left.\frac{\widehat{v_{o}}(s)}{\widehat{v_{c}}(s)}\right|_{{\widehat{l_{R}}}_{\text {dist }}=0}$ & $\operatorname{Voc}(s)=\frac{1}{R i} \cdot \frac{T i(s)}{1+T i(s)} . Z(s)$ \\
\hline $\operatorname{Vou}(s)=\left.\frac{\widehat{v_{o}}}{\hat{u}}\right|_{\widehat{\iota}_{R} \text { dist }}=0$ & $\operatorname{Vou}(s)=\frac{\operatorname{Voc}(s)}{1-\operatorname{Voc}(s) \cdot \frac{R_{F F}}{R_{E Q}}}$ \\
\hline$\left.Z o_{F F}(s) \stackrel{\text { def }}{=} \frac{\widehat{v_{0}}(s)}{\hat{\imath}_{\text {Rdist }}(\mathrm{s})}\right|_{\widehat{u}=0}$ & $Z o_{F F}(s)=\frac{Z o(s)+R_{F F} \cdot \operatorname{Voc}(s)}{1-\frac{R_{F F}}{R_{E Q}} \cdot \operatorname{Voc}(s)}$ \\
\hline
\end{tabular}


Table VI. Gains and Transfer functions of the chosen controllers

\begin{tabular}{l|c}
\hline \multicolumn{1}{c|}{ Name } & Expression \\
\hline \hline Voltage sensor gain, $\beta$ & $18 \mathrm{~m} \Omega$ \\
\hline Current sensor gain, $R i$ & $1.85 \Omega$ \\
\hline Current feed-forward gain, $R_{F F}$ & $1.65 \Omega$ \\
\hline Output Voltage controller & $G_{v}(s)=\frac{5500}{s} \cdot \frac{\left(1+\frac{s}{75}\right)}{1+\frac{s}{628318}}$ \\
\hline Output Current controller & $G_{i}(s)=\frac{20532}{s} \cdot \frac{\left.1+\frac{s}{125665}\right)}{1+\frac{s}{251327}}$ \\
\hline & $L P F(s)=\frac{1}{1+\frac{\omega_{n}^{2}}{40000 \cdot \pi}} \cdot \frac{\left(1+\frac{1}{s^{2}+2 . \zeta . \omega_{n} \cdot s+\omega_{n}^{2}}\right.}{\sqrt{2}, \omega_{n}=\frac{400000 \cdot \pi}{3}}$ \\
\hline \hline
\end{tabular}

